\title{
Development and Integration of RFID Simulation Based Tool for Improved Schedule Performance in Saudi Arabia Precast Concrete Industry
}

\author{
Thamer Alzuriq, Mohamed Essam Shaawat, Altayeb Qasem,
}

\begin{abstract}
A construction project is measured as a process that encompasses numerous activities and a huge amount of information of numerous types that are related to each other. Effective project management entails controlling all aspects of a construction project: quality and quantity of work, costs, and schedules to guarantee the accomplishment of the project. The construction industry in the kingdom of Saudi Arabia is implementing off-site construction with precast cement, for its higher quality, short cycle time, and negligible environmental influence. Amongst the various off-site construction approaches, such construction follows a manufacturing method where houses are built in smaller panels in an assembly line. Owing to the complex and exclusive nature of the home building process, prevailing manufacturing concepts such as automated production planning and control system are not applicable to the panelized home production facility. This research aims in the development and integration of radio frequency identification (RFID) technology to for production planning and control system, resulting in improved schedule performance, in Saudi Arabia precast concrete industry. Radio frequency identification is appropriate to numerous construction applications and generates cost savings via increased speed and accuracy of data entry. The study provides a set of helpful protocols for the deployment of passive RFIDs for automated on factory management of precast concrete operations. Further it aims at paving the way for managing the site for the sake of attaining the desired goals considering the guarantee of achieving high quality and quick conveyance to the related sites which, hence, prompts auspicious conveyance of development ventures. The study is beneficial for the construction professionals to assess the prevailing construction quality perception and the expectations from implementation of any quality improvement technique in construction projects.

Keywords: Radio frequency identification [RFID], Construction works, Precast management, just in time [JIT], Simulation program, Indoor location sensing.
\end{abstract}

\section{INTRODUCTION}

Over past five years Saudi Arabian housing industry has

Revised Manuscript Received on April 15, 2020.

* Correspondence Author

Eng. Thamer Alzuriq*, Department of Building Engineering, College of Architecture and Planning, Imam Abdulrahman Bin Faisal University, P. O. Box 1982, Dammam 31441. Saudi Arabia. Email: thamer444_ksa@hotmail.com

Dr. Mohamed Essam Shaawat, Professor, Department of Building Engineering, College of Architecture and Planning, Imam Abdulrahman Bin Faisal University, P. O. Box 1982, Dammam 31441. Saudi Arabia. Email: mshaawat@iau.edu.sa

Dr. Altayeb Qasem, Assistant Professor, Department of Building Engineering, College of Architecture and Planning, Imam Abdulrahman Bin Faisal University, P. O. Box 1982, Dammam 31441. Saudi Arabia. Email: aqasem@iau.edu.sa

(C) The Authors. Published by Blue Eyes Intelligence Engineering and Sciences Publication (BEIESP). This is an open access article under the CC BY-NC-ND license (http://creativecommons.org/licenses/by-nc-nd/4.0/) highly improved especially by enhancing the efficiency and the quality of the output produced[1]-[6]. The overall atmosphere of the industry has improved mainly through the various interventions in the field of RIFD. RIFD has enhanced various techniques used in the field of housing demonstrating various techniques to enhance the tasks at hand [7]-[15]. Mostly these techniques are focused on improved arrangement of manufacturing procedures in order to be able to reach the main objectives within the organization. These end objectives are also in favor of the overall industry at large.
Published By:

Blue Eyes Intelligence Engineering \& Sciences Publication (C) Copyright: All rights reserved. 


\section{Development and Integration of RFID Simulation Based Tool for Improved Schedule Performance in Saudi Arabia Precast Concrete Industry}

\begin{tabular}{|c|c|c|c|c|c|c|}
\hline Project & Location & $\begin{array}{l}\text { Total } \\
\text { Area }\end{array}$ & $\begin{array}{c}\text { Date } \\
\text { Launched }\end{array}$ & $\begin{array}{l}\text { Scheduled } \\
\text { Completion }\end{array}$ & Value(SAR) & $\begin{array}{l}\text { Residential } \\
\text { Area }\end{array}$ \\
\hline $\begin{array}{l}\text { King Abdullah } \\
\text { Economic City } \\
\text { (KAEC) }\end{array}$ & $\begin{array}{l}\text { Rabigh, } \\
\text { north of } \\
\text { Jeddah }\end{array}$ & $\begin{array}{l}168 \\
\text { million sq. } \\
\mathrm{m} .\end{array}$ & Q42005 & 2016 & 100 Billion & $\begin{array}{l}\text { Includes } \\
260,000 \\
\text { apartments and } \\
56,000 \text { villas }\end{array}$ \\
\hline $\begin{array}{l}\text { Prince Abdulaziz bin } \\
\text { Mousaed Economic } \\
\text { City (PABMEC) }\end{array}$ & $\begin{array}{l}\text { Hail, north } \\
\text { of Riyadh }\end{array}$ & $\begin{array}{l}156 \\
\text { million sq. } \\
\mathrm{m} .\end{array}$ & Q2 2006 & 2018 & 30 Billion & $\begin{array}{l}\text { Develop } 30,000 \\
\text { housing units }\end{array}$ \\
\hline $\begin{array}{l}\text { Knowledge Economic } \\
\text { City (KEC) }\end{array}$ & $\begin{array}{l}\text { Holy city of } \\
\text { Medina }\end{array}$ & $\begin{array}{l}4.8 \text { million } \\
\text { sq. } \mathrm{m} \text {. }\end{array}$ & Q2 2006 & 2014 & 25 Billion & $\begin{array}{l}\text { Develop } 30,000 \\
\text { residential units }\end{array}$ \\
\hline $\begin{array}{l}\text { Jazan Economic City } \\
\text { (JEC) }\end{array}$ & $\begin{array}{l}\text { Jizan, } 725 \\
\text { kms south } \\
\text { of Jeddah }\end{array}$ & $\begin{array}{l}100 \\
\text { million sq. } \\
\mathrm{m} .\end{array}$ & Q42006 & 2011 & 102 Billion & $\begin{array}{l}\text { Include } \\
\text { residential } \\
\text { areas with } \\
\text { complete } \\
\text { amenities }\end{array}$ \\
\hline
\end{tabular}

Figure 1. Launching of four integrated economic cities by Saudi government[16]

The Saudi government has launched four integrated economic cities and is launching another two later this year one in Tabuk and one in the Eastern Province (Fig 1). These huge projects aim to meet residential and commercial property needs and to improve the investment climate in the country. The study focuses on the development of this industry not only on the regional but also on the international level especially through the shared vision and enhanced experience focusing on the improved business procedures. RIFD has also focused on improving the concrete development and passive automated management in this field [8]-[10]. More importantly this study also focuses on enhancing the procedures for guaranteeing the achievements through essential goal attainment and guaranteeing the quality of work and improving the development of various procedures involved in the process.

The study suggests that it is extremely important that accurate methods should be adopted especially for various sources of productivity and to track the efficiency of the overall procedure. The use of RIFD would support the industry in improving the level of output for the workers and for enhancing the quality of the management information transferred to the managers. Moreover, RIFD in Saudi Arabia housing techniques have helped in not only generating the required information but also for tracking the right set of information for controlling and for improved progress report in various construction projects. RIFD has also developed an online interface which helps in facilitating the flow of information between different organizational sector and also for sharing the information at larger level and at an improved speed and accuracy.

\section{LITERATURE REVIEW}

A significant number of past researchers have mostly tended to investigate the various aspects of RFID[17]-[29]. The accompanying works will survey a portion of the works that have been done identifying the required laps for extraresearch studies. According to[30], [31], the attainment of the required data of the current site that manages and controls the progression of work depends fundamentally on the nature, exactness, recurrence and time of that site for the sake of pursuing and control of development ventures. Another studies [32]-[35] discussed the issues related to the current manual procedures in order to identify, trace and recognize the pre-manufactured materials with excellent standards which sometimes lead to delay in receipt and unclear nature of the components, and incorrect installations that lead to delay of working hours and increase labor costs. Moreover, a study by [36], [37]identified the management of weak materials as a major source of low productivity for construction, cost overruns and delays. However, it is difficult to obtain this accurate information effectively because of the nature of the industry and due to large or intensive projects which result in failure to track materials effectively and to access the information required to schedule delays and additional labor costs. The study of [38], [39] identified and expounded the use of the RFID tag and reader to gather information, and then the multi-faceted and packed information such as the quantity of production, the quantity of materials, and the conformity of achieving the quality standards, stock status, and transportation management information which in turn are transferred to the manager's office or the worker's site via DPA or internet.

Numerous automated data collection techniques have been employed to automate the process of obtaining data required for tracking performance, control and progress report in construction projects. These techniques included technology of barcode[40]-[44], RFID [45]pen-based computers[46] [49], [50]-[53], Photogrammetry [38], [39], [42], [54], [55], and multimedia technology (Abeid and Arditi, 2002). Researchers also developed an online interface to facilitate the flow of information among project participants during the monitoring process[56], [57]. For example, bar code coding was introduced in 1973 by[58]-[63]. Automated data collection methods play an important role in enhancing the speed and accuracy of data acquisition in a cost-effective manner. The automated quality management system, which is so easy, can help to integrate promising information technologies such as RFID technology and web portals to increase the efficiency and flexibility of information flow, so that radio frequencies are compatible with many construction applications and save costs by increasing speed and accuracy of data entry[38], [64]-[66]. Researchers [38], [66]-[68] indicated that RFID systems have labels or transponders that are equipped with features including a receiving wire and a scanner. The tag contains a small circular chip and a receiver that is enclosed in a protected shell. It is also trusted that RFID includes the utilization of

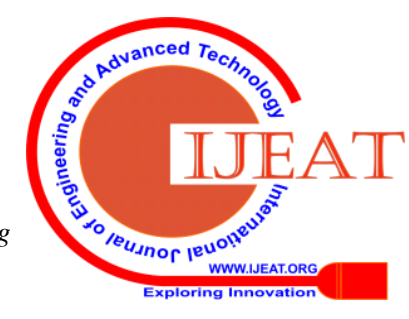


little read/compose small scale transmitters that can store information in a strong situation while RFID information can be put away in labels and recovered with pursuers who can speak with labels utilizing radio recurrence waves rather than light waves as in barcoding. The cost of RFID depends for the most part on the recurrence utilized and on the sort of labels, uninvolved or dynamic. The frequencies are isolated into low frequencies, high, and extremely high. Other studies by [69]-[72] showed that low frequency can be 124 $\mathrm{KHz}, 125 \mathrm{KHz}$, or $135 \mathrm{KHz}$ and their range can vary from as low as few centimeters to $0.33 \mathrm{~m}$ whereas High frequency tags use $13.56 \mathrm{MHz}$ and can read from up to $3.3 \mathrm{~m}$. Ultrahigh frequency use 860 to $960 \mathrm{MHz}$ and read from a distance that ranges from 3.3 to $100 \mathrm{~m}$. Its alos states that dynamic labels have a battery and more costly than detached labels that can be charged from the peruser. Labels can be examined as it were or read-write labels, and the read-write labels can be read-many write-once or read-many writemany. The read-only labels are modified as it were once Dynamic labels depend on inside batteries for their control supply, which altogether improves their studied ranges and empowers extra onboard memory and neighborhood detecting. Be that as it may, utilizing a nearby control source limits their lifetime to 5-10 a long time and increments their prices (Montaser, 2013). Akinci et al (2002) mentioned that RFID labels have different determinations, such as their control source, recurrence, examined extend, perused rate, information capacity, measure, operational life, and their costs as well.

However, [30], [31], [73]-[75]demonstrates that later progresses in computerized information securing innovations have empowered the utilize of sets of sensors for recognizable proof, area detecting, and following the developments of objects. Area distinguishing proof gives bolster for the decision-making prepare and is pivotal for the convenient following of venture status. He also displayed a framework planned to track fabric conveyance vehicles, material-handling gear and following concrete conveyance vehicles. In addition, he proposed a better approach of utilizing RFID innovation in following precast concrete pieces and overseeing data related with them all through a supply chain. Clearly stated, the determination of the identity in construction projects in development ventures is a as of late advancing range in which the area of assets can be utilized to procure exact data around venture status.The findings of the study elucidate that:

The relationship between the velocity of the reader and the rate of finding out the error is a direct one; the diffused reading rate of RFID has a direct connection with the efficiency of zone configuration; the results showed that the error ratio in the observed medium was much lower than in the construction site; and the constant reader functions and fulfills superior results than the animated reader. This study presents a group of the most useful protocols that are used for the spread of radio frequency identifications in the field of automatic site management that is adopted in the construction of processes[42], [76]-[79].

Our investigation and findings indicate that, we have lack in production and Identification tools for precast concrete elements in the gulf regions and particularly in the Kingdom of Saudi Arabia focusing more on the specially at the production, storage, and delivery. Most studies however were done in western world with very limited knowledge of work done in the Middle East. Thus, making this study very beneficial to ease the construction sector. Data is usually stored in paper form, which can be lost or misrepresented, also if have any computer software is updated by the programmer. Problems with manual methods for identifying, tracking and identifying custom-made components result in delayed deliveries, dual handling, dislodging of components, improper equipment that leads to scheduling delays and increased labor costs. In a nutshell this study will develop a management tool based on RFID technology for precast concrete elements in Saudi Arabia.

\section{METHODOLOGY}

The current conducted study has been carried out to match the operative usage of RFID technology that is implemented mainly in constructions taking into consideration that the adoption of GPS is no longer possible to be used. RFID deployment for interior zone identification is considered the major concern of the present study which in turn aims to avail a cluster of procedures that are related to the deployment of RFIDs that are used in building construction as well as other tags including topologies, distance of the deployed tags, and stationary versus moving reader user, zone configuration and moving target speed.

The effect of these variables on the performance of closed area technology and the ability to detect and analyze it is considered very important because it provides a rational for optimal propagation and closest for RFID tags in the relevant location. There were several different scenarios for this study, and the researcher here believes that this study is optimal because it fits the current study and methodology of the study.

The present study shows the application of the passive RFID technology that aids in mastering locative data for the inside zone where passive tag of RFID is used a point that indicates the identified position among the zone that has been defined in advance. The denoted point is marked as a transmitter with a space that is pre-defined and is majorly applied to evaluate the position of the target point that is being tracked with reference to its immediacy. The active area of indoor construction work is categorized into limited zones for tracing. Considering the space, each zone is shielded by a subgroup of passive RFID tags that are not costly. The current study included a sample of (the Closeness of passive reference tags. 2RR (4m)) that addressed the requirements of the experiment.

[80]-[83]indicated that K-NN algorithm is the best method that is mostly used in such studies and the best one that meets the demands finding out solutions for this type of problems. This study considered the K-NN method for grouping various objects with reference to the most proximal examples the researcher arrived at in the feature space.

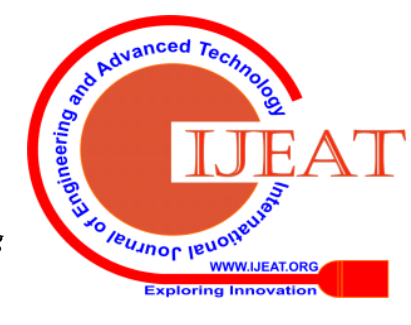


Development and Integration of RFID Simulation Based Tool for Improved Schedule Performance in Saudi Arabia Precast Concrete Industry

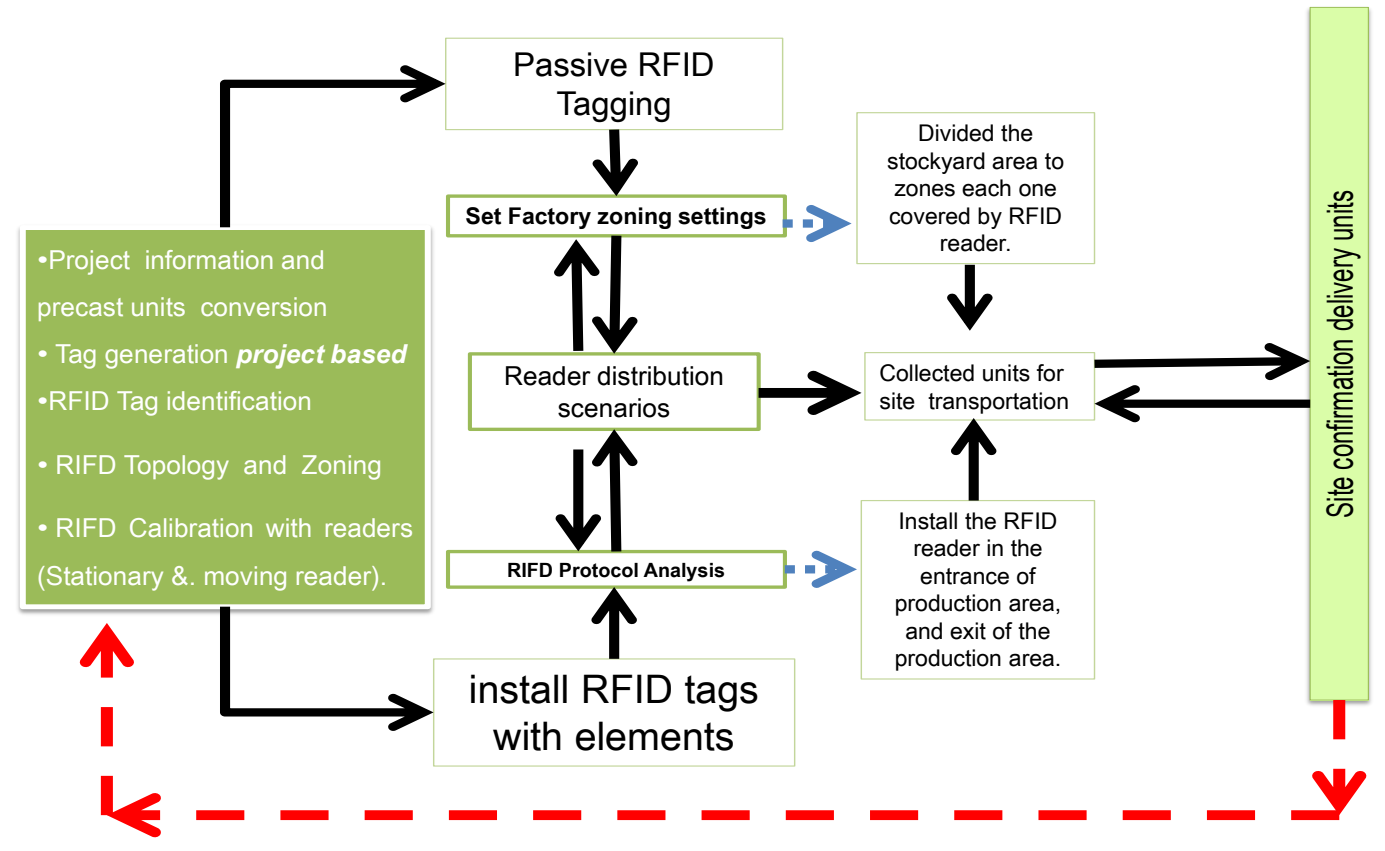

3.1 Methodology Summary

3.1.1 Analysis of Data

3.1.1.1 Simulation implementation

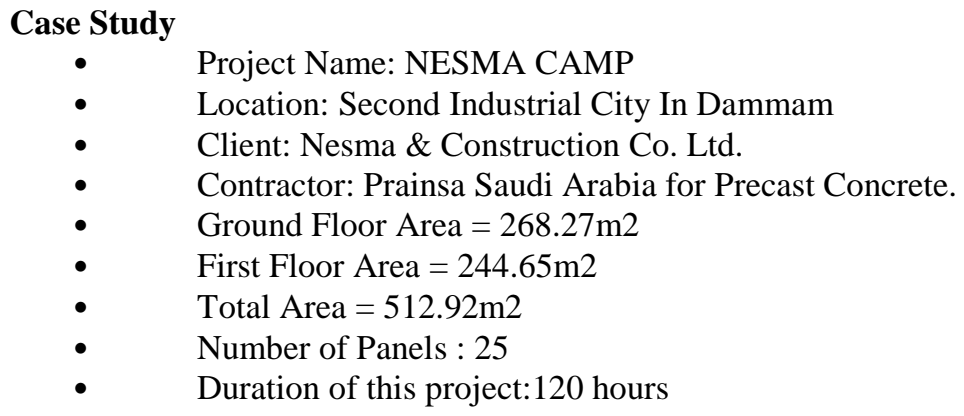

- $\quad$ Location: Second Industrial City In Dammam

- $\quad$ Client: Nesma \& Construction Co. Ltd.

- $\quad$ Contractor: Prainsa Saudi Arabia for Precast Concrete.

- $\quad$ Ground Floor Area $=268.27 \mathrm{~m} 2$

- $\quad$ First Floor Area $=244.65 \mathrm{~m} 2$

- $\quad$ Total Area $=512.92 \mathrm{~m} 2$

- $\quad$ Number of Panels : 25

- Duration of this project:120 hours
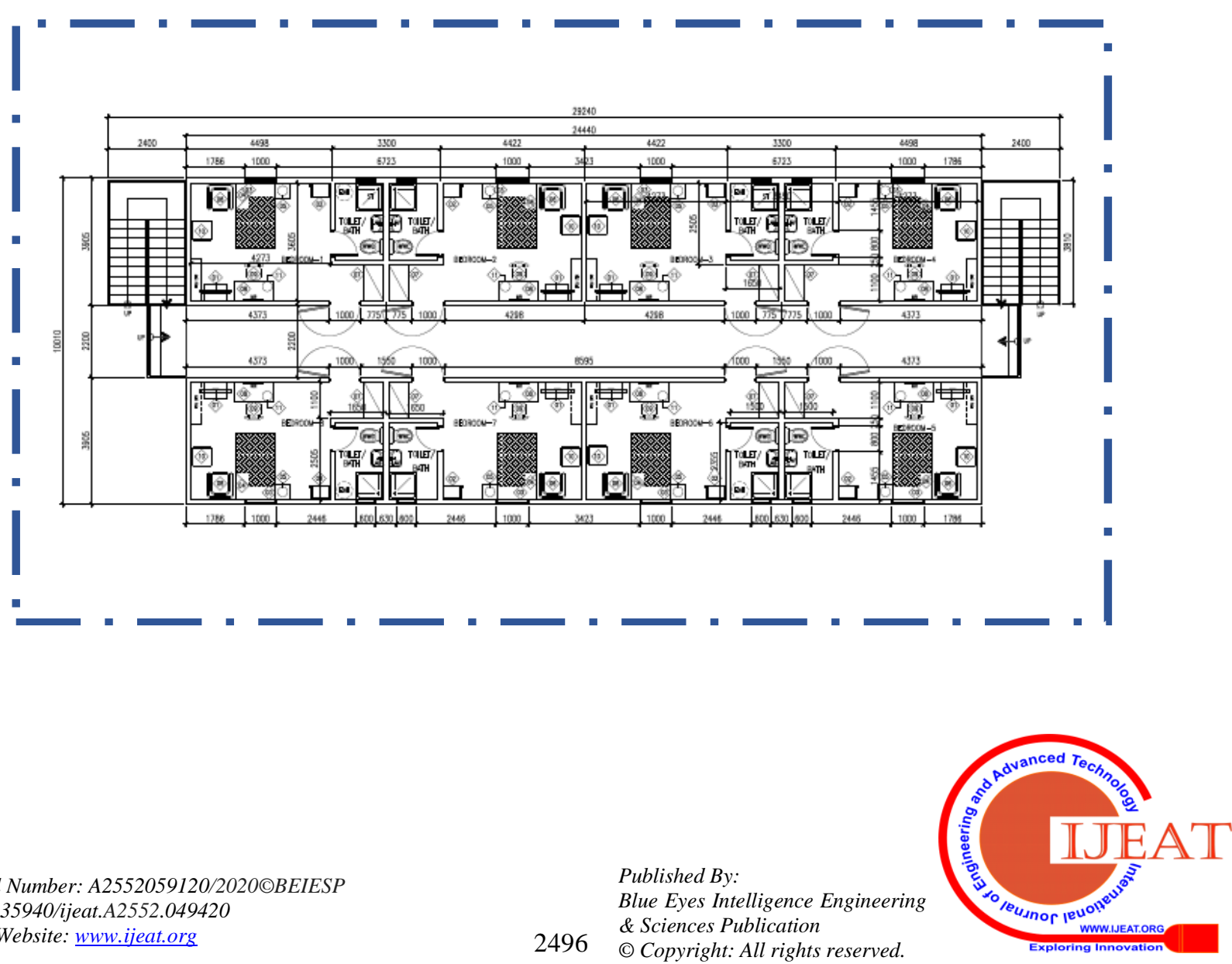
The precast production management system model design:

\section{$>$ Design phase:}

1. The client will bring the drawings for the project to be constructed.

2. Determines the expected loads on the building.

3. The company prepare (GID) general integration drawings.

4. Send the drawings for client to approve or modify the notes.

5. Manufacturing drawings (shop drawings) \& coding drawings (Manual) for all projects.

\section{$>$ Encoding phase:}

Etch company have special system to encoding element
1. Projects number.
2. Elements number.
3. Sub elements number.
4. Lists of element.

List of element to be used by production , storage and delivery

\section{Production Phase :}

Current flow chart depicting processes for pre-cast production
1. The production department schedules the projects and make daily report manual.

2. To defined the element he used the manual labile.

3. labor Install the labile for all element.

4. After casting element update report manual.

\section{Storage Phase :}

1. Demolding / stocking elements and reported.

2. Update report manual.

\section{Delivery Phase :}

Most element tracking problems involve:

1. Time consuming identification and determination of location.

2. Error-prone data recording and documentation.

3. delayed information.

Site Phase :

1. Don load the elements from the track.

2. Determine the element location.

3. Eructation for precast elements.

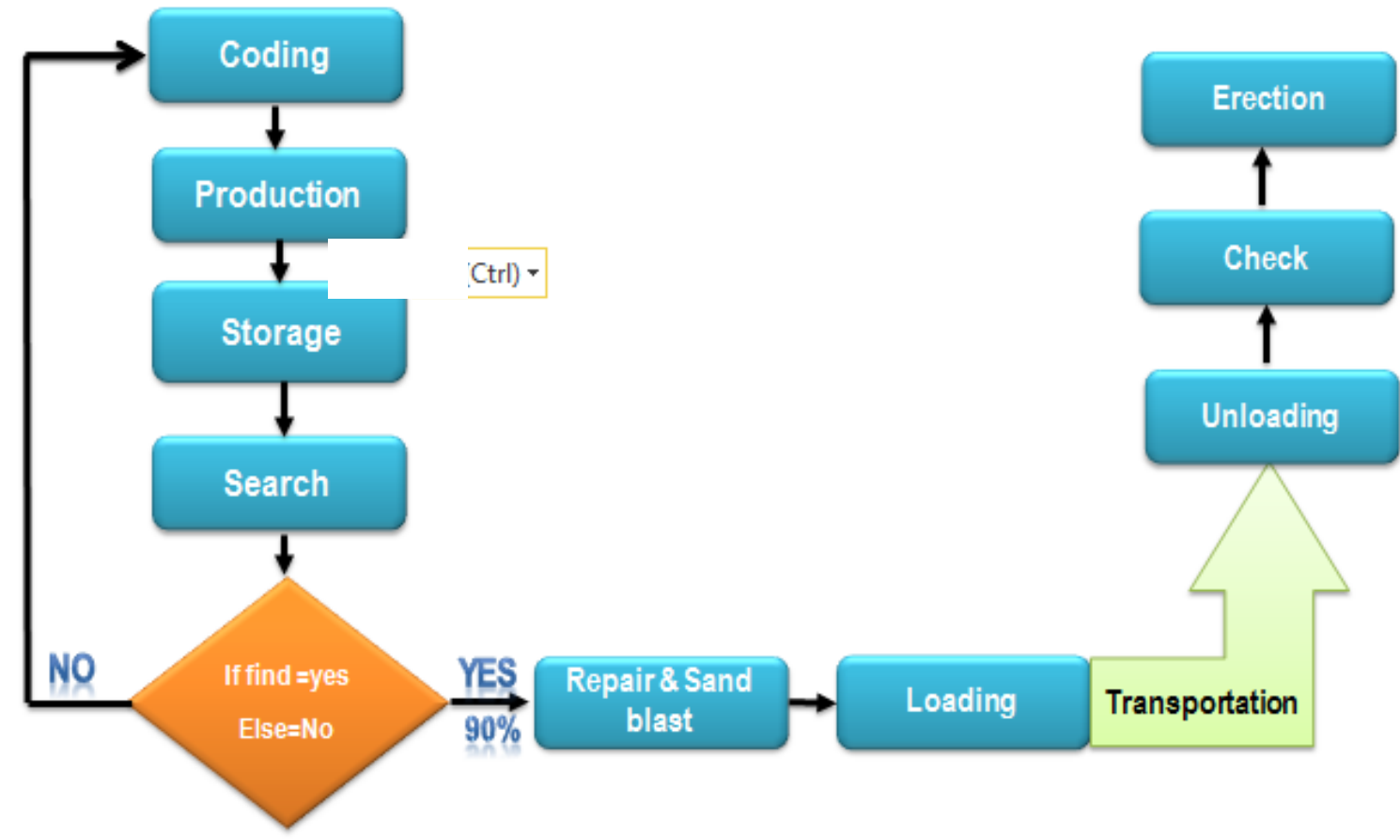

Current Model precast production processes input

Precast production processes input

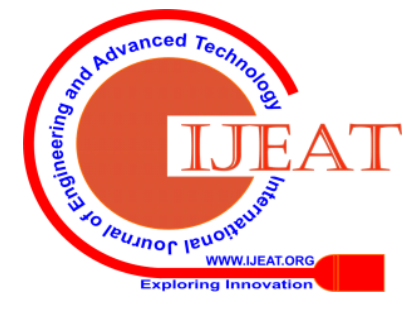


Development and Integration of RFID Simulation Based Tool for Improved Schedule Performance in Saudi Arabia Precast Concrete Industry

\begin{tabular}{|l|l|l|l|l|}
\hline$\#$ & Processes & Min. & Most. & Max. \\
\hline $\mathbf{1}$ & Production & $12 \mathrm{~h}$ & $16 \mathrm{~h}$ & $18 \mathrm{~h}$ \\
\hline $\mathbf{2}$ & Storage & $00: 12 \mathrm{~h}$ & $00: 15 \mathrm{~m}$ & $00: 30 \mathrm{~h}$ \\
\hline $\mathbf{3}$ & Search & $\mathbf{1 h}$ & $\mathbf{1 8 h}$ & $\mathbf{3 0 h}$ \\
\hline $\mathbf{4}$ & Repair \& Sand blast & $00: 15 \mathrm{~h}$ & $00: 25 \mathrm{~h}$ & $00: 30 \mathrm{~h}$ \\
\hline $\mathbf{5}$ & Loading & $00: 10 \mathrm{~h}$ & $00: 13 \mathrm{~h}$ & $00: 15 \mathrm{~h}$ \\
\hline $\mathbf{6}$ & Transportation & $00: 45 \mathrm{~h}$ & $1: 30 \mathrm{~h}$ & $2 \mathrm{~h}$ \\
\hline $\mathbf{7}$ & Unload & $00: 10 \mathrm{~h}$ & $00: 13 \mathrm{~h}$ & $00: 15 \mathrm{~h}$ \\
\hline $\mathbf{8}$ & Check & $00: 10 \mathrm{~h}$ & $00: 13 \mathrm{~h}$ & $00: 15 \mathrm{~h}$ \\
\hline $\mathbf{9}$ & Erection & $00: 30 \mathrm{~h}$ & $00: 45 \mathrm{~h}$ & $1 \mathrm{~h}$ \\
\hline
\end{tabular}

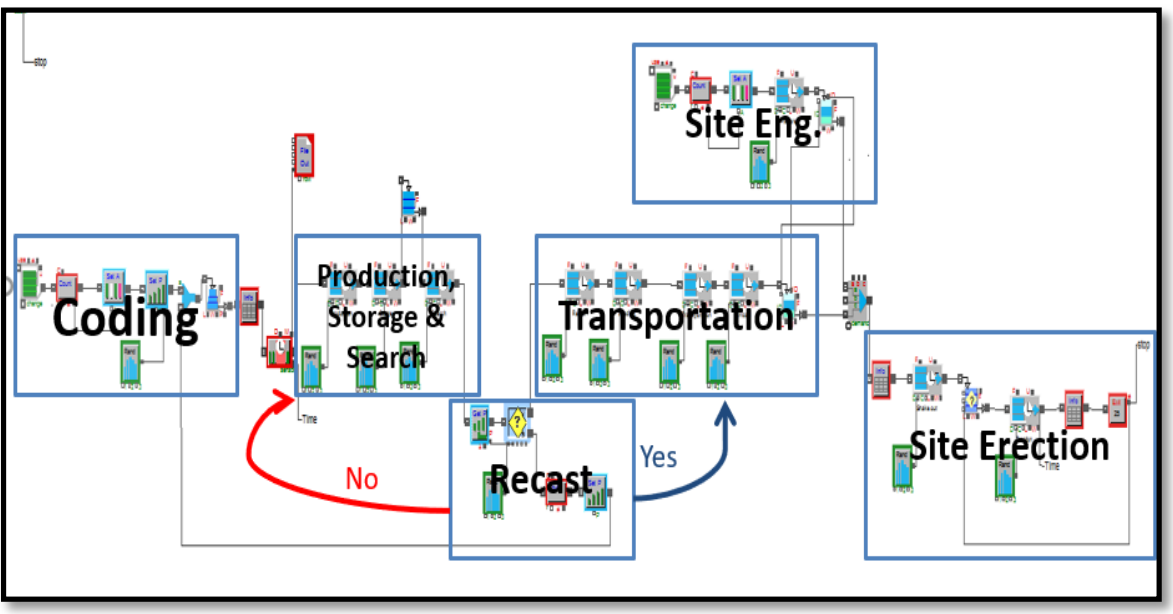

In order to verify the effectiveness of the program used in the RFID simulations, the current situation of the program must be entered and the actual results achieved by inserting all stages of the work (classification, manufacturing, storage, research and linkage until it reaches the installation
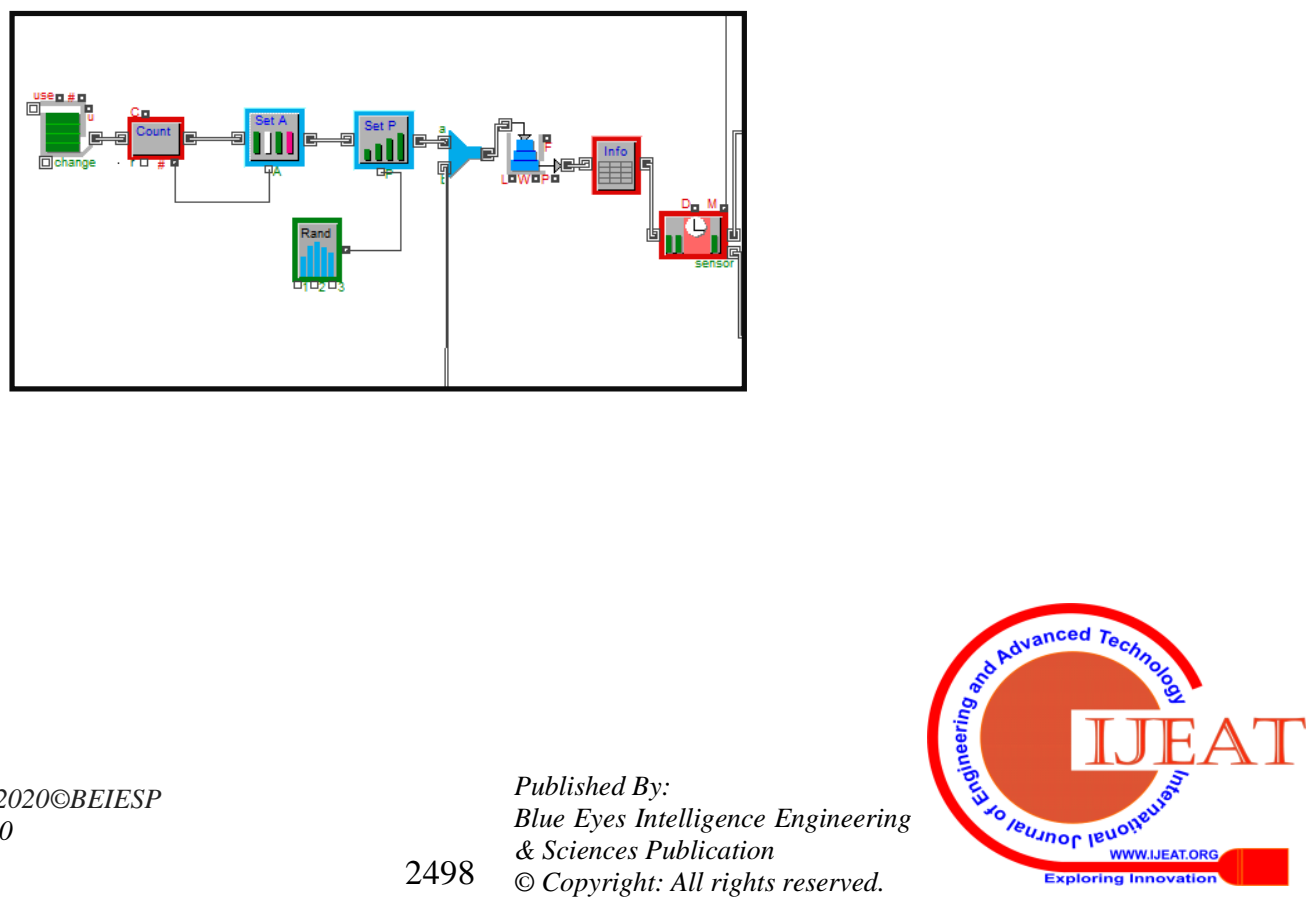

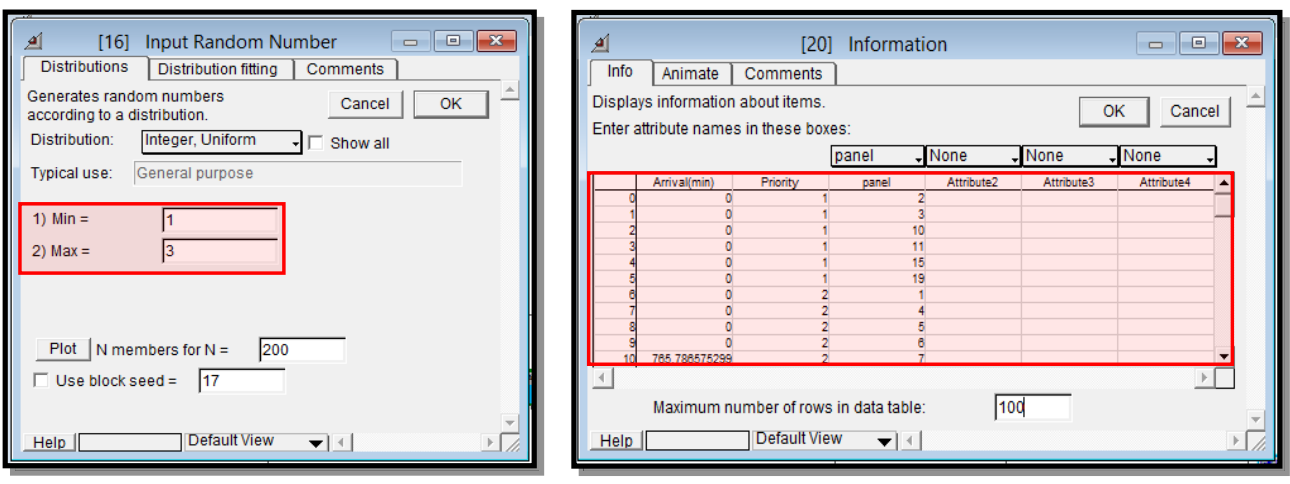

At this stage, the panel to be manufactured are sorted and entered into the manufacturing stage randomly. This was done by using a command that gives importance to each set of blocks randomly from one to three as shown in Fig.6.

$$
\text { I }
$$

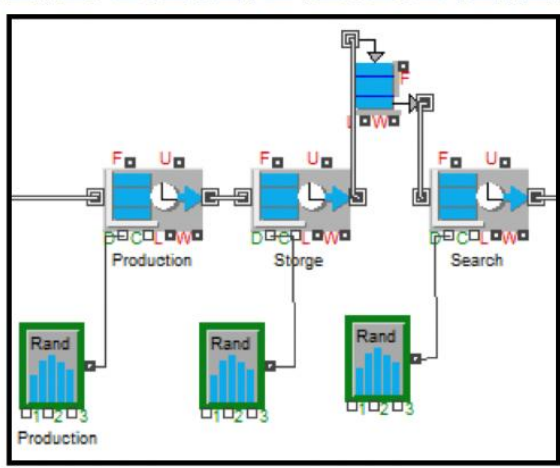

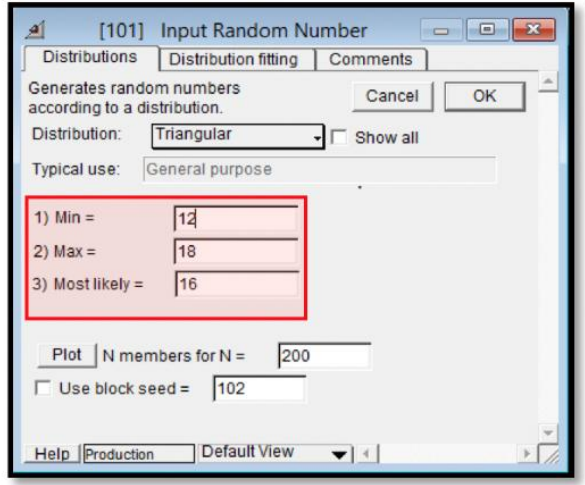

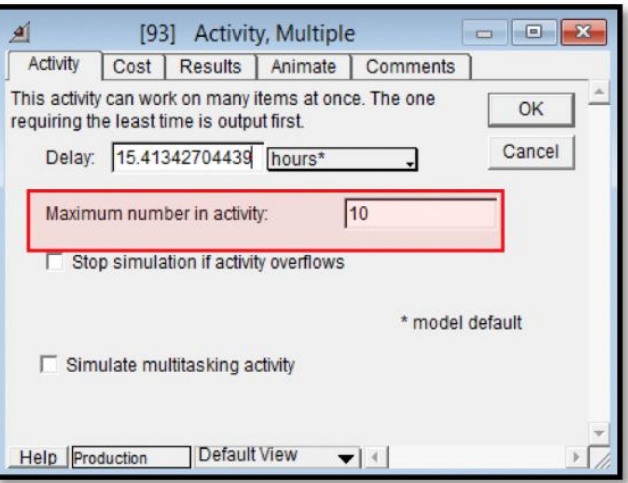


Development and Integration of RFID Simulation Based Tool for Improved Schedule Performance in Saudi Arabia Precast Concrete Industry
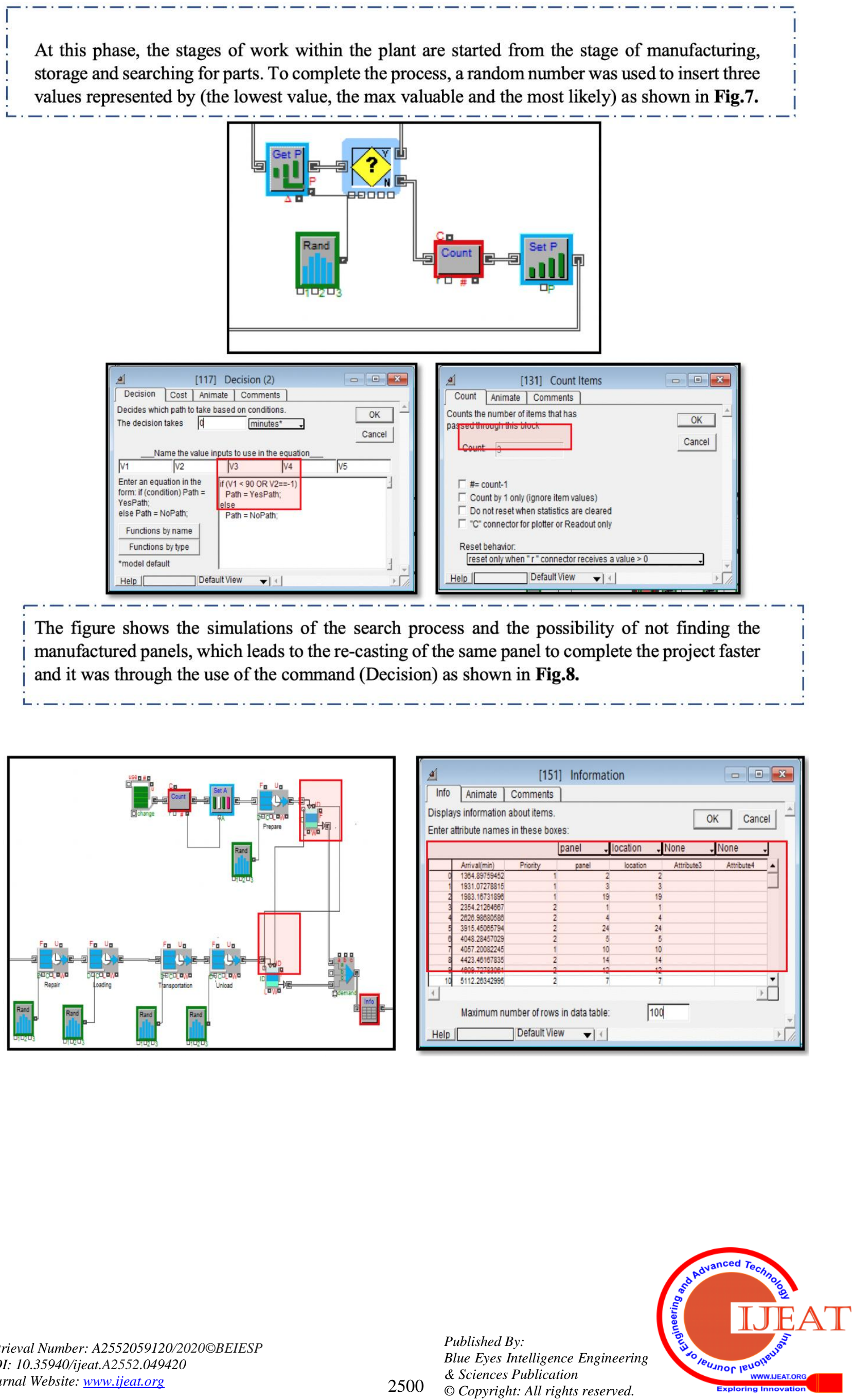

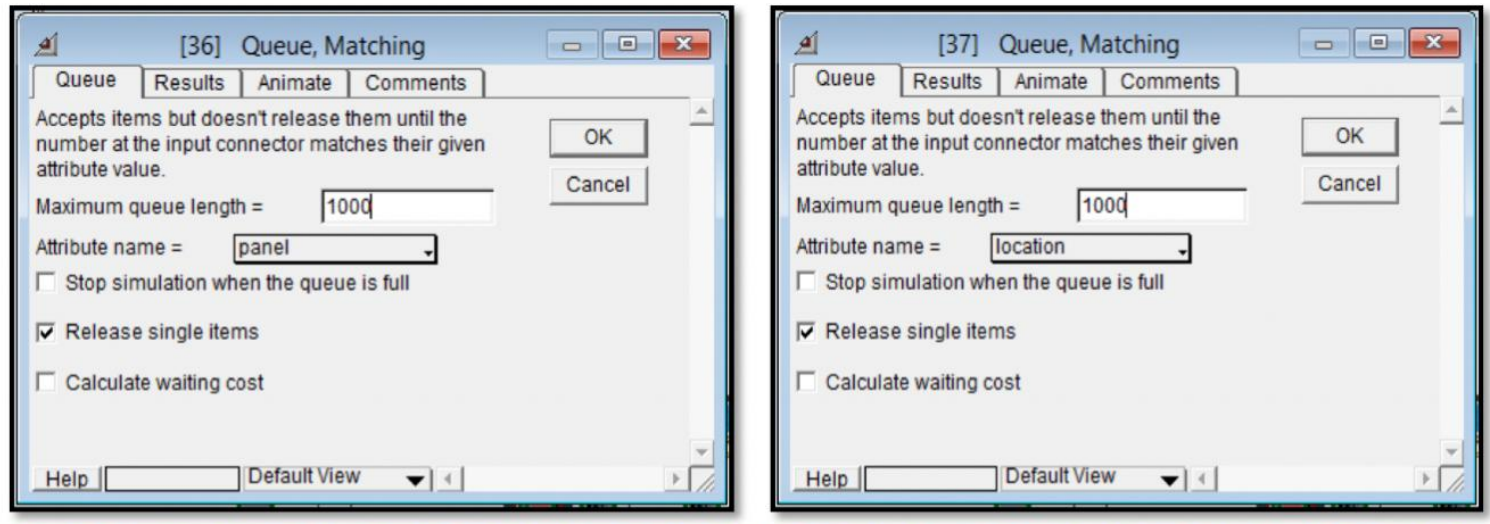
The previous figure shows the simulations of the current mode of manufacturing and sending the panels to the site randomly, where the site engineer takes the task of classifying the pieces based on the existing installation plans. We note in Figure (9) the approaching of panel number 2 before panel number one, which assures the need to store the panels until the appropriate panel arrives ! and this causes delay in completing the project.

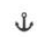
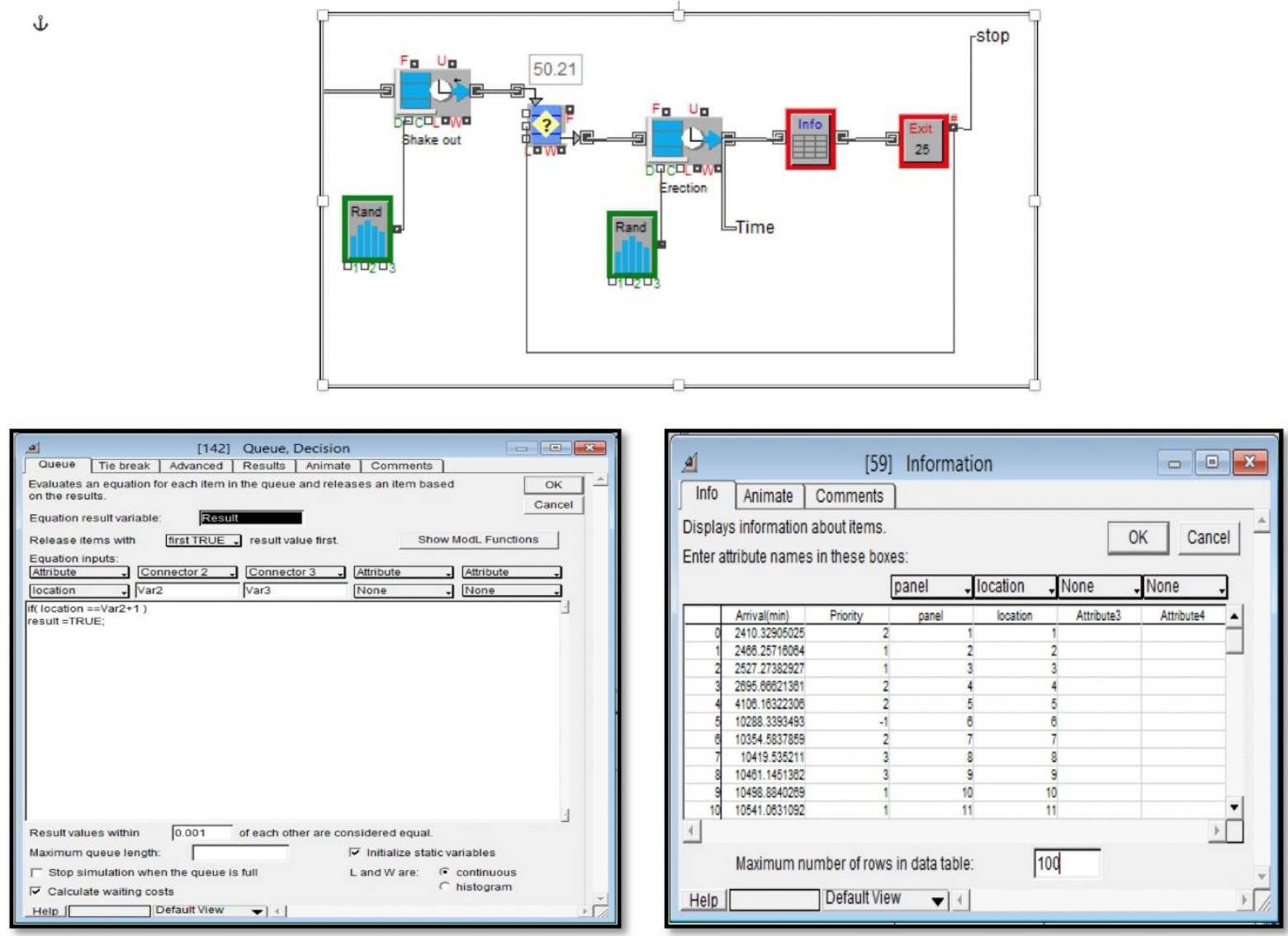

It this stage, the task of the site engineer has been simulated after the arrival of all panel to the i site to install the panel in the given order in the charts. It is clear that the number of waiting hours i reached 50 hours, and that is equivalent to five working days as shown in this Figure.10.

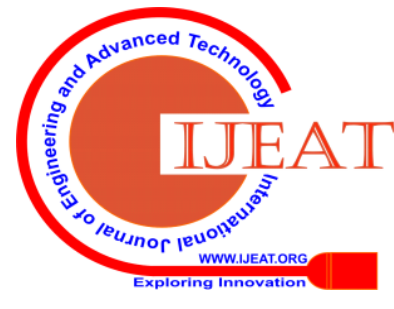


Development and Integration of RFID Simulation Based Tool for Improved Schedule Performance in Saudi Arabia Precast Concrete Industry

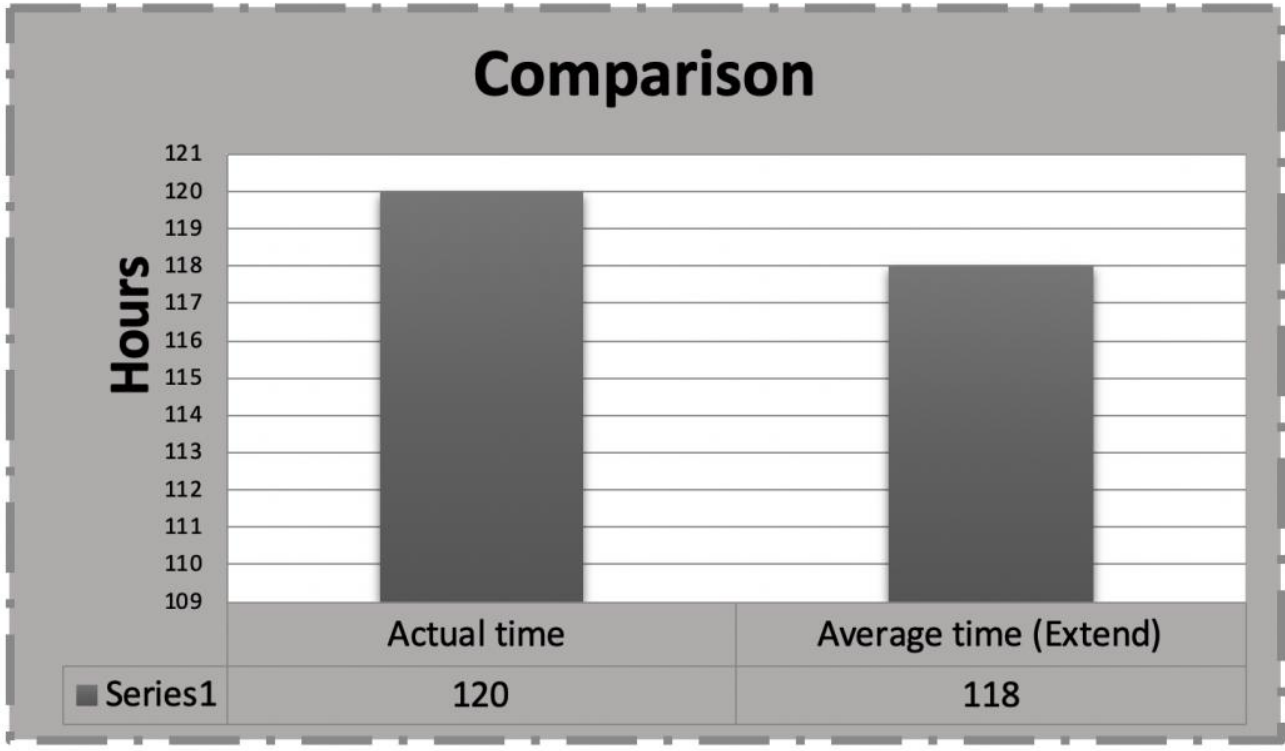

This graph shows the degree of compatibility of the program to reality where the proportion of i compliance is $80 \%$.

To-be flow chart depicting processes for pre-cast production

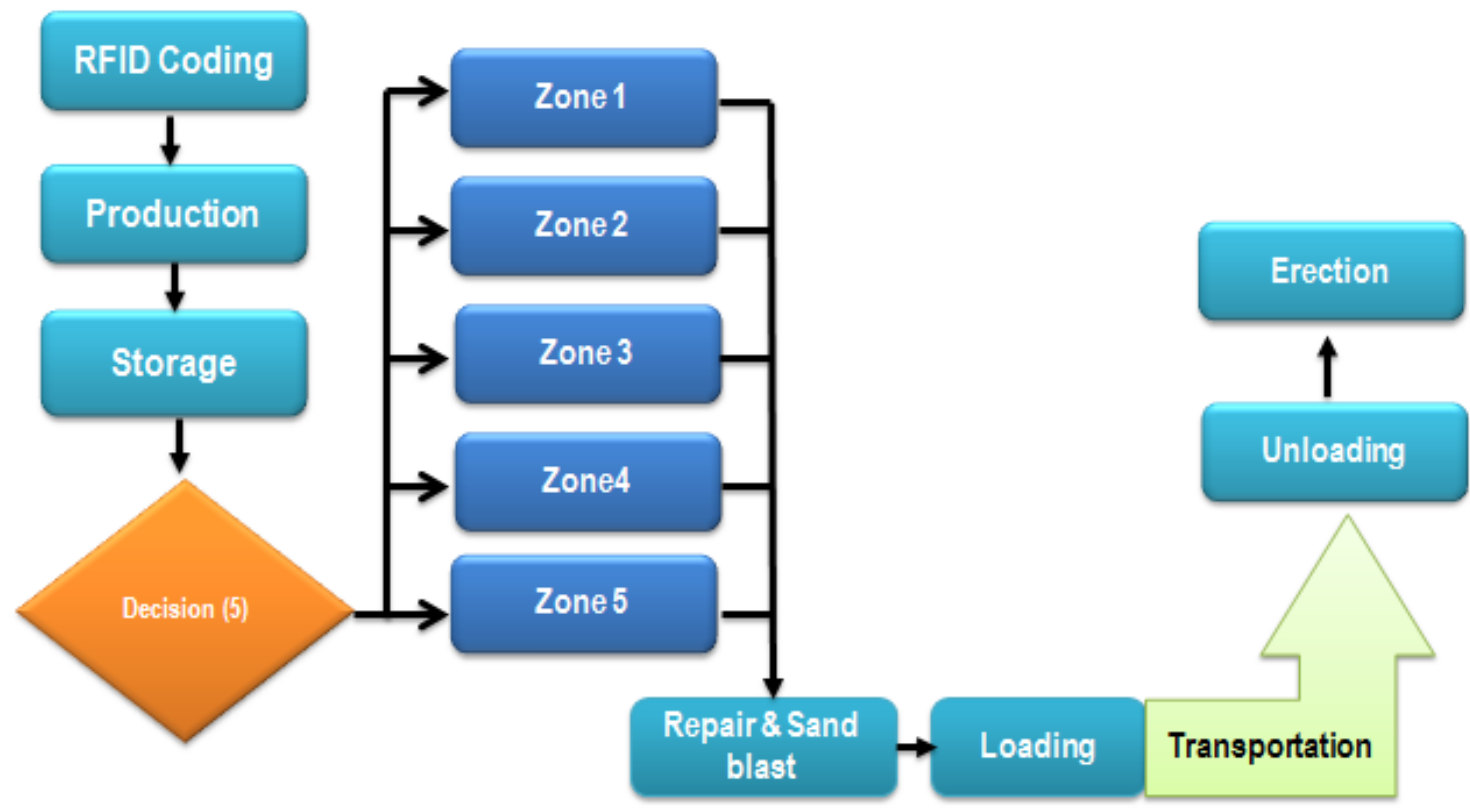

Development of storage area:

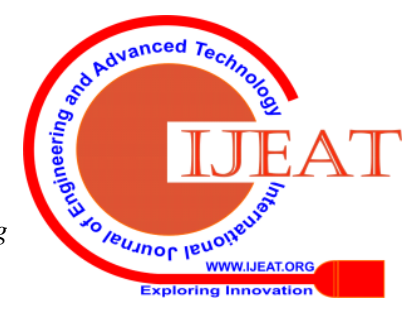




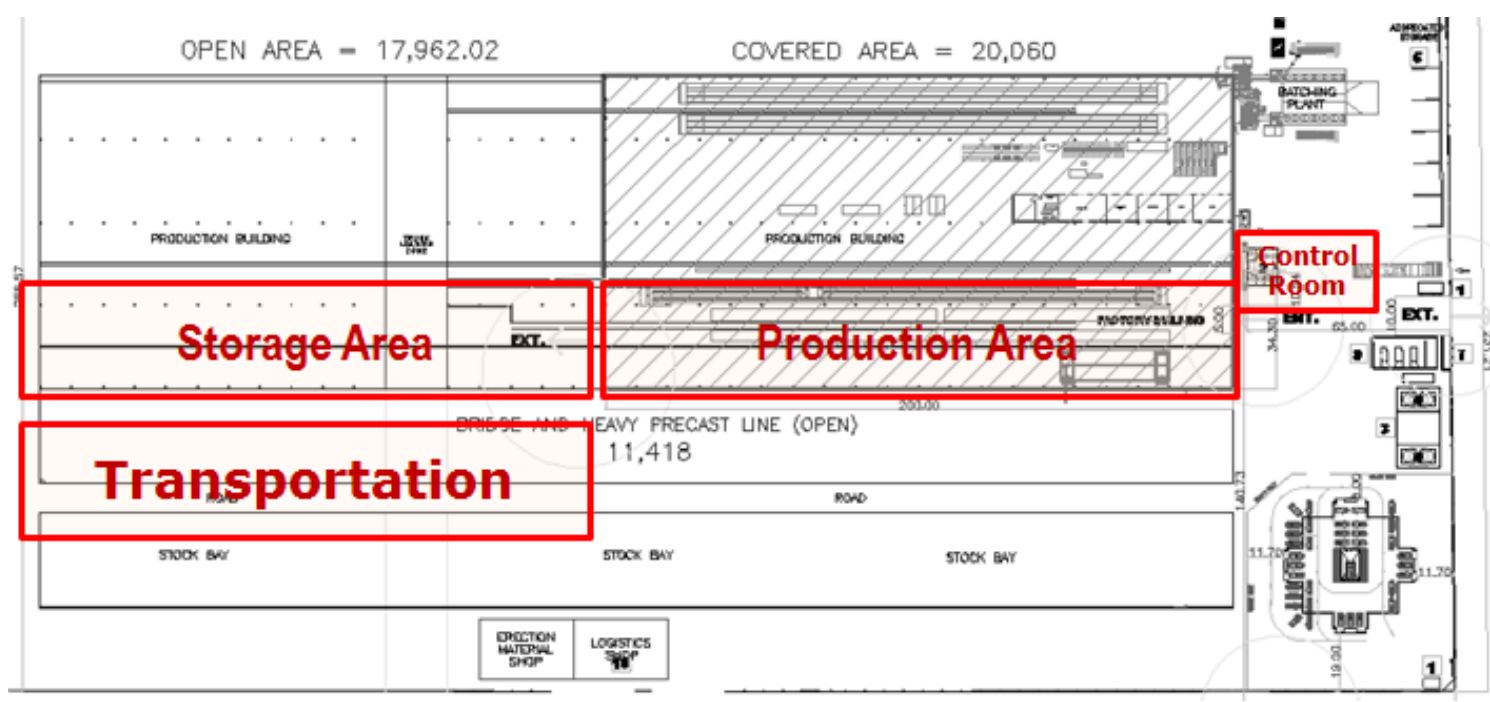

The current situation for storage area as shown in this Figure.11.

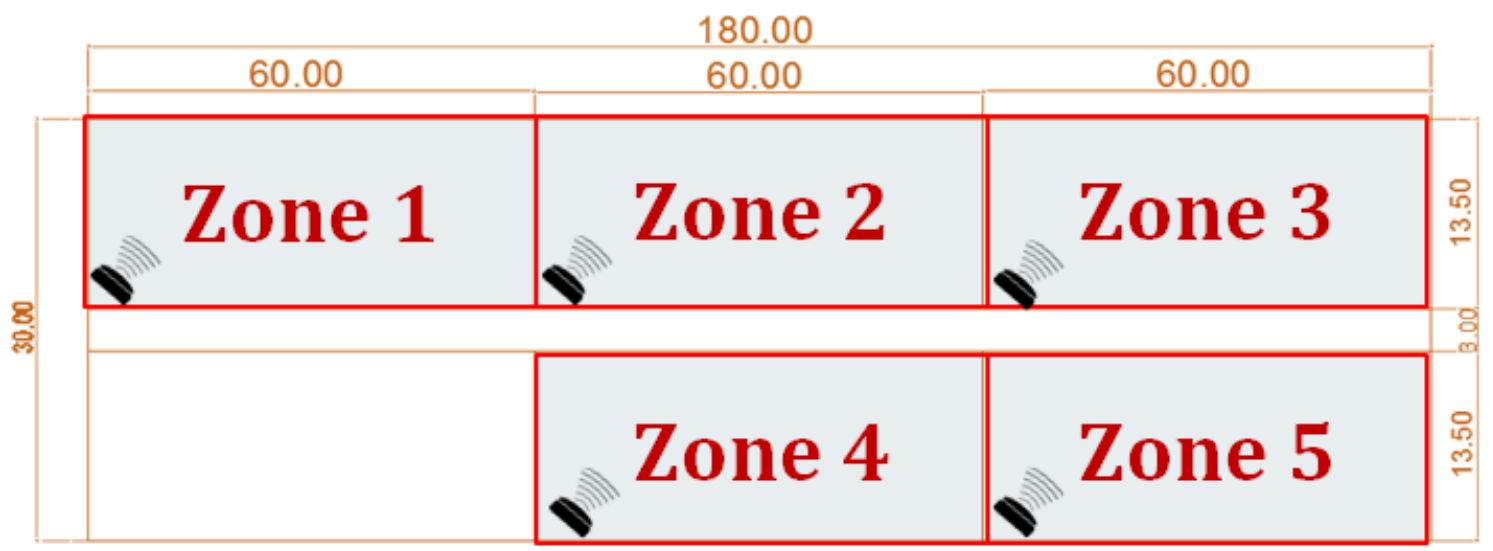

based on RFID topology and to minimize reader the KNN - protocol was adopted and presented as shown in this Figure.12.

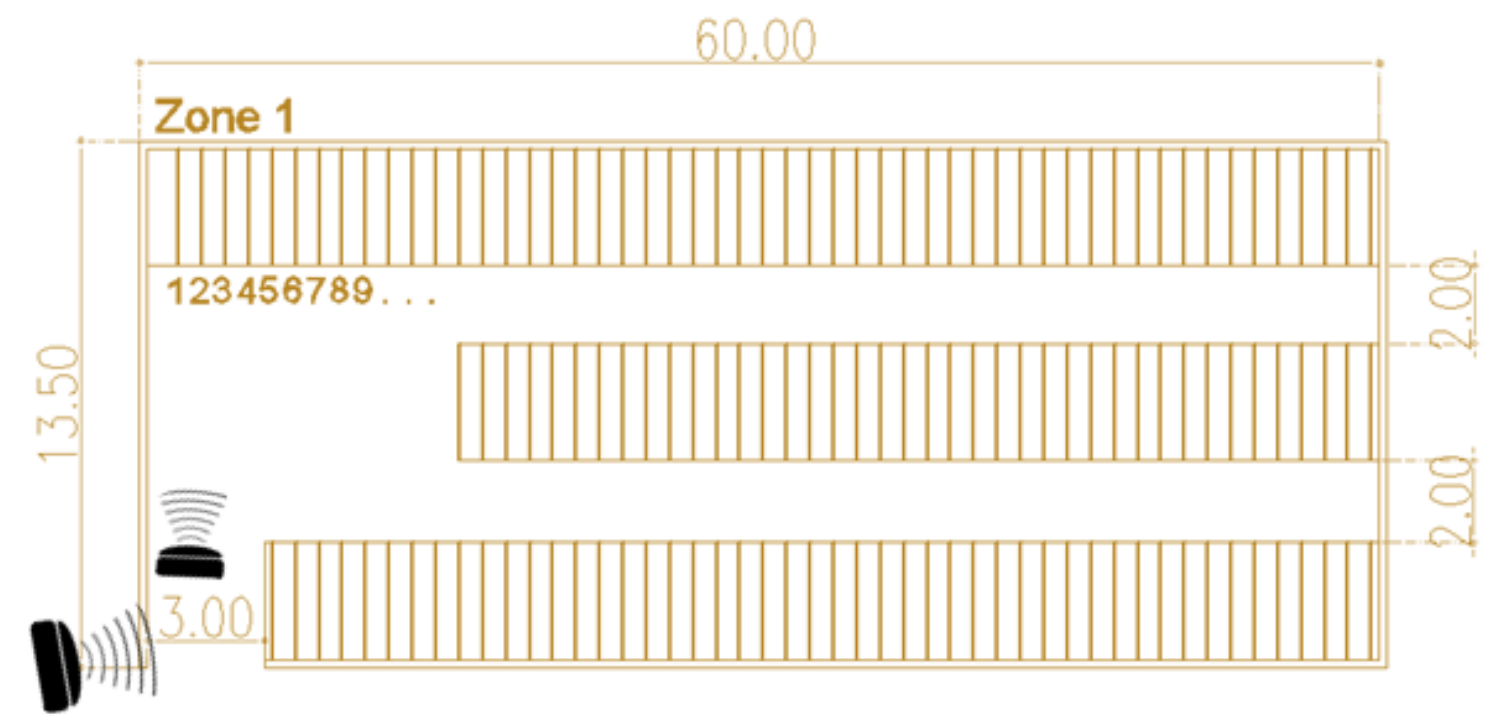

Based on the use of the Closeness of passive reference tags. 2RR (4m). Each zone is formatted so at the entrance to each zone use the Stationary RFID reader reads all the precast elements passing through it and then search of the elements to be sent to the site is done by using the moving RFID reader as shown in this Figure.13.

Published By:

Blue Eyes Intelligence Engineering

\& Sciences Publication 

Saudi Arabia Precast Concrete Industry

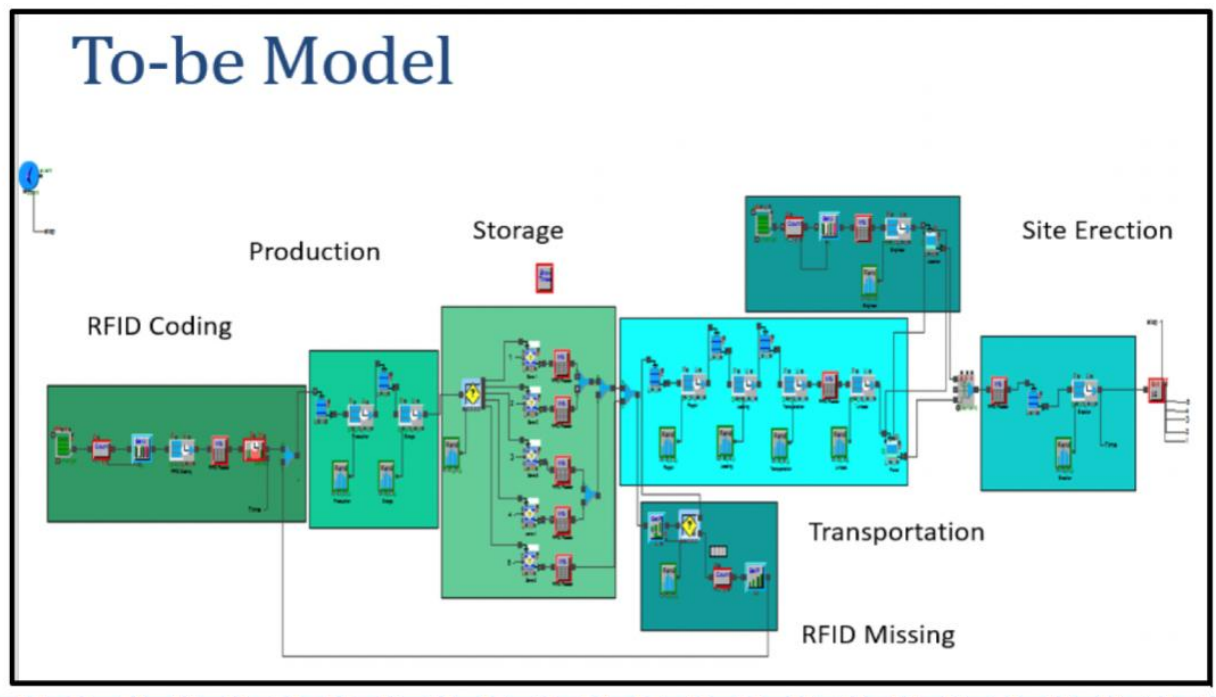

Fig.14. Here, the model was introduced using the RFID hypothesis as shown in the figure to i simulate the system and measure its effectiveness and comparison with the previous model.
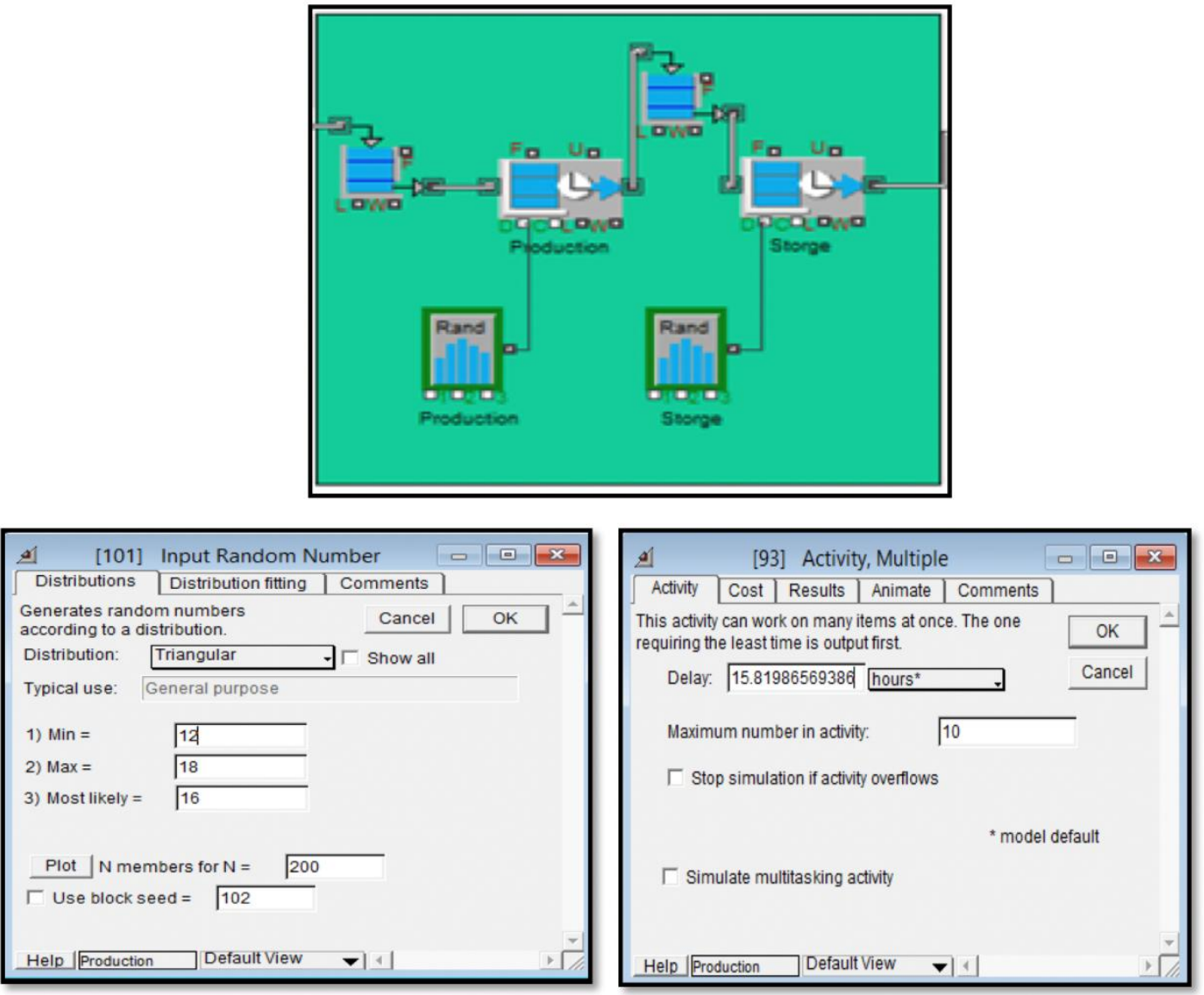

The above figure shows the introduction of the factory work stages starting from the manufacturing and storage stages. The command (Random Number) is used to introduce three values represented by (the lowest value, the most valuable and the most frequent) as shown in Figure (15).

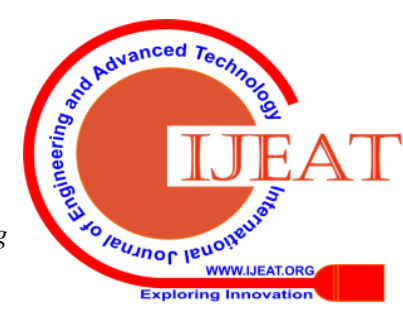



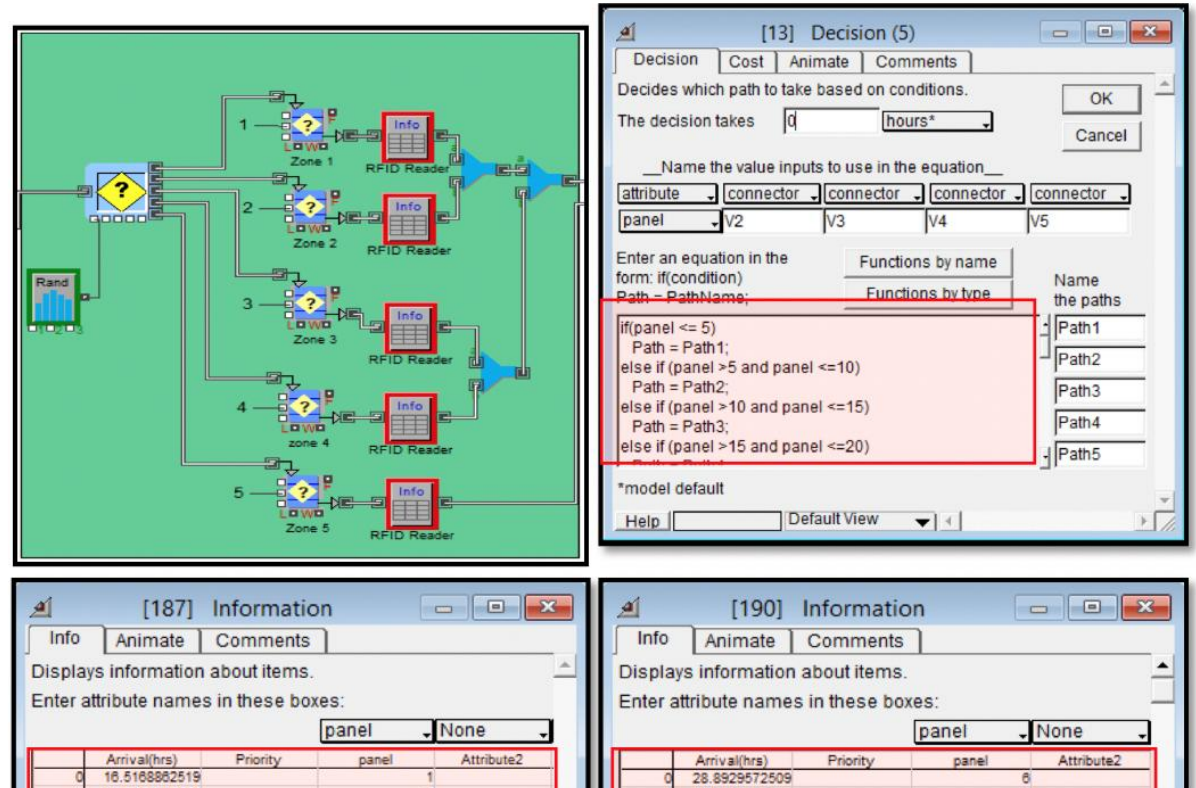
\begin{tabular}{|l|l|l|}
\hline Info & Animate & Comments \\
\hline
\end{tabular} Displays information about items.

Enter attribute names in these boxes:
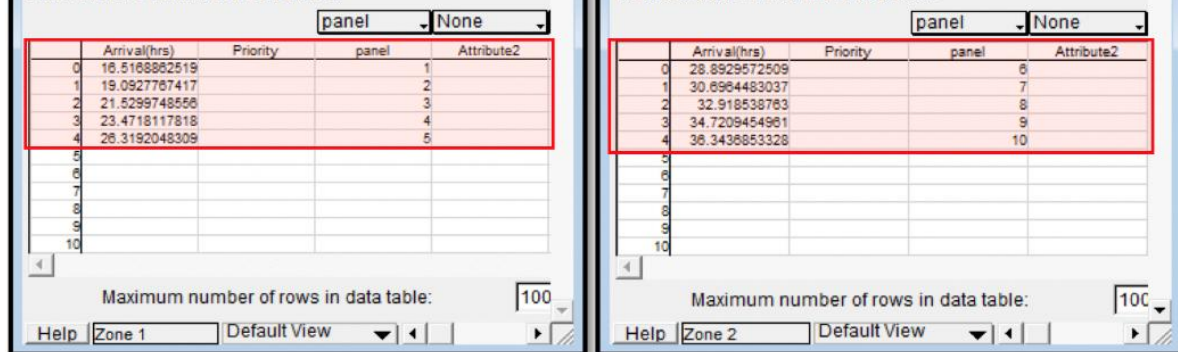

Help Zone 1 Default View $\mathbf{7} \mid \mathbf{1}$

1 Maximum number of rows in data table: $\quad \sqrt{10 \mathrm{C}}$

In this step, the rearrangement of the storage process was simulated so that the panel could be

|reached faster by using the "Decision 5" command as shown in the figure (16).
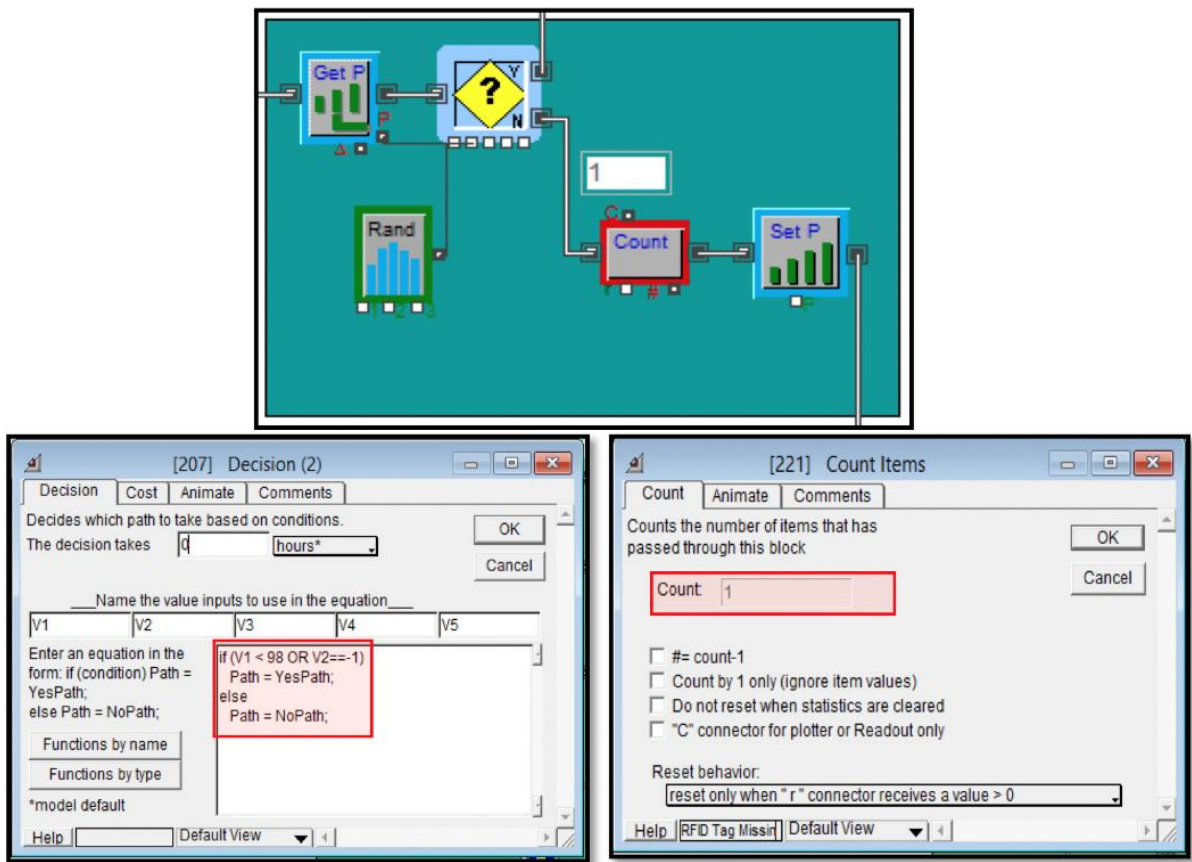

Published By:

DOI: 10.35940/ijeat.A2552.049420

Journal Website: www.ijeat.org
Blue Eyes Intelligence Engineering

\& Sciences Publication

(C) Copyright: All rights reserved.

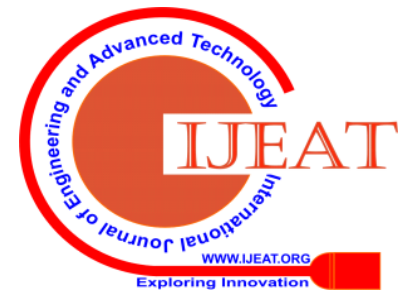


Development and Integration of RFID Simulation Based Tool for Improved Schedule Performance in Saudi Arabia Precast Concrete Industry

Fig.17. Here the probability of RFID tag is applied and given $2 \%$. In this case the item is

re-searched or re-manufactured.

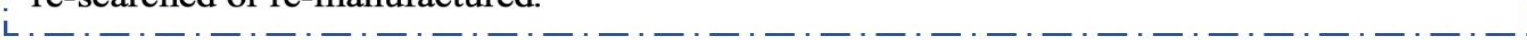

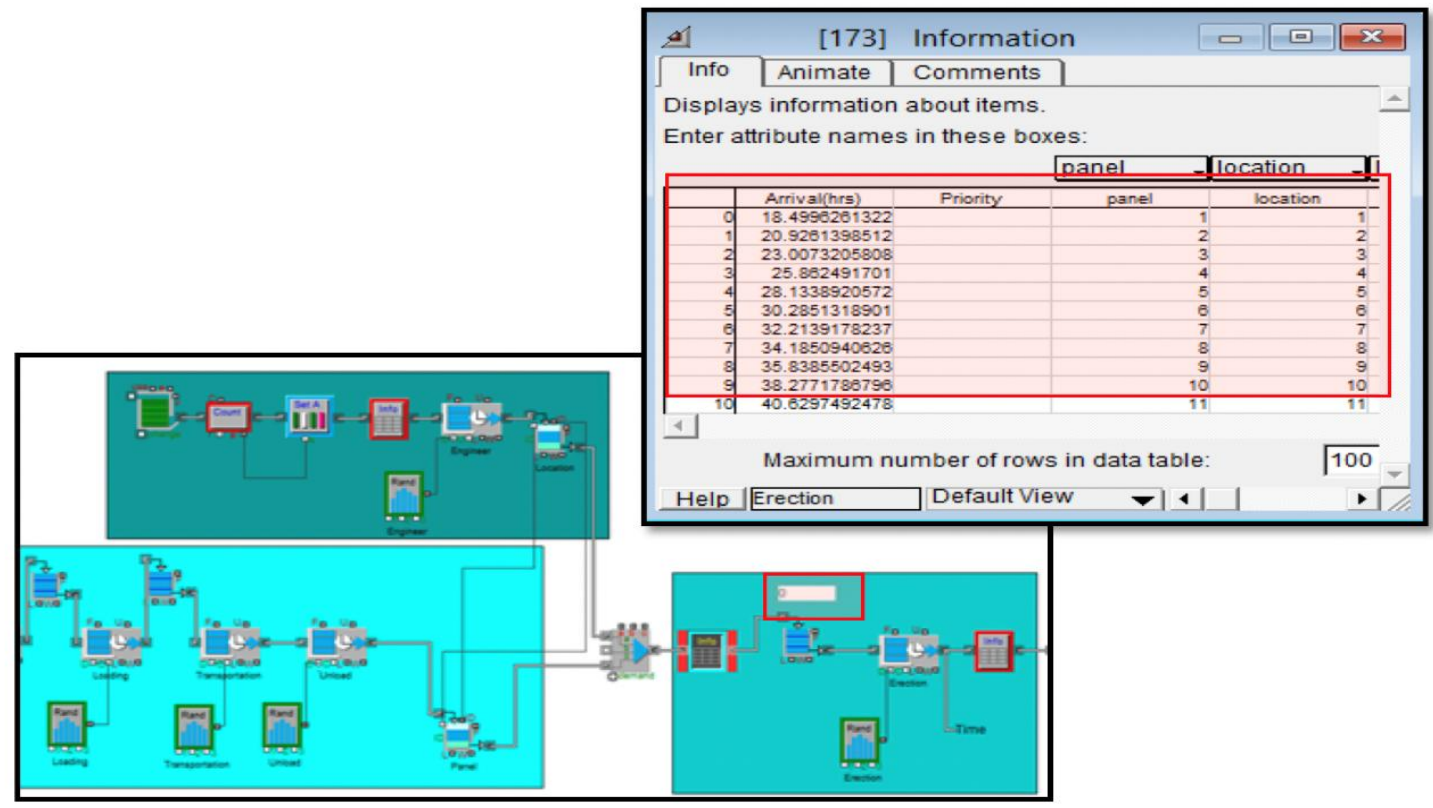

This phase shows the arrival of the panel to the site in a neat manner, which corresponds to the needs of the site as shown in the previous figure(18). It is worth mentioning that there is no longer a need to store the precast panel on the site, which saves time and delivery of the site on time.

4.0 Finding \& Results

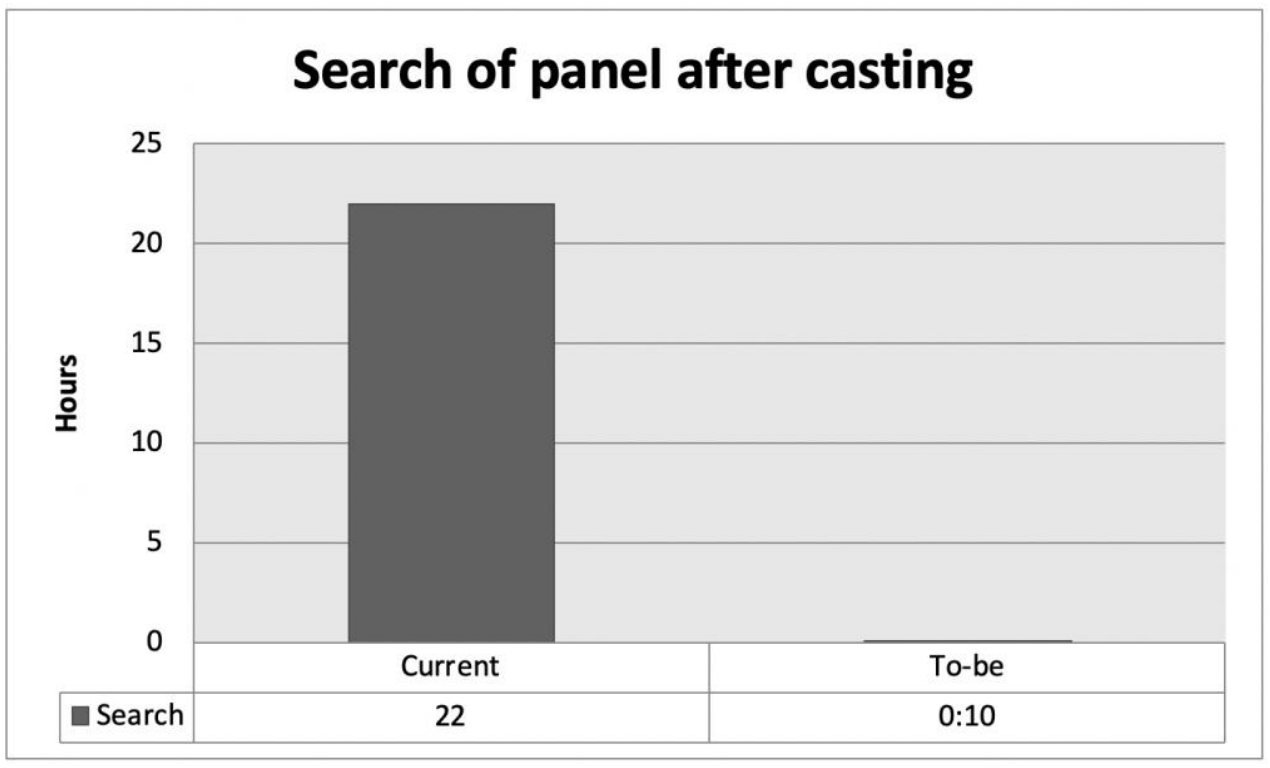

Fig.19. This charts showing the average wait time need it for the search of the each element after casting in storage

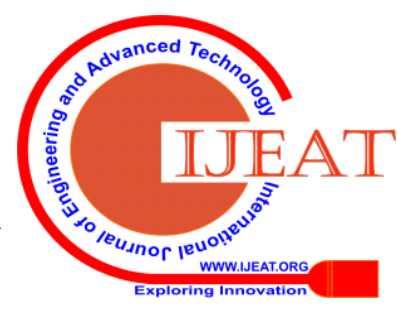




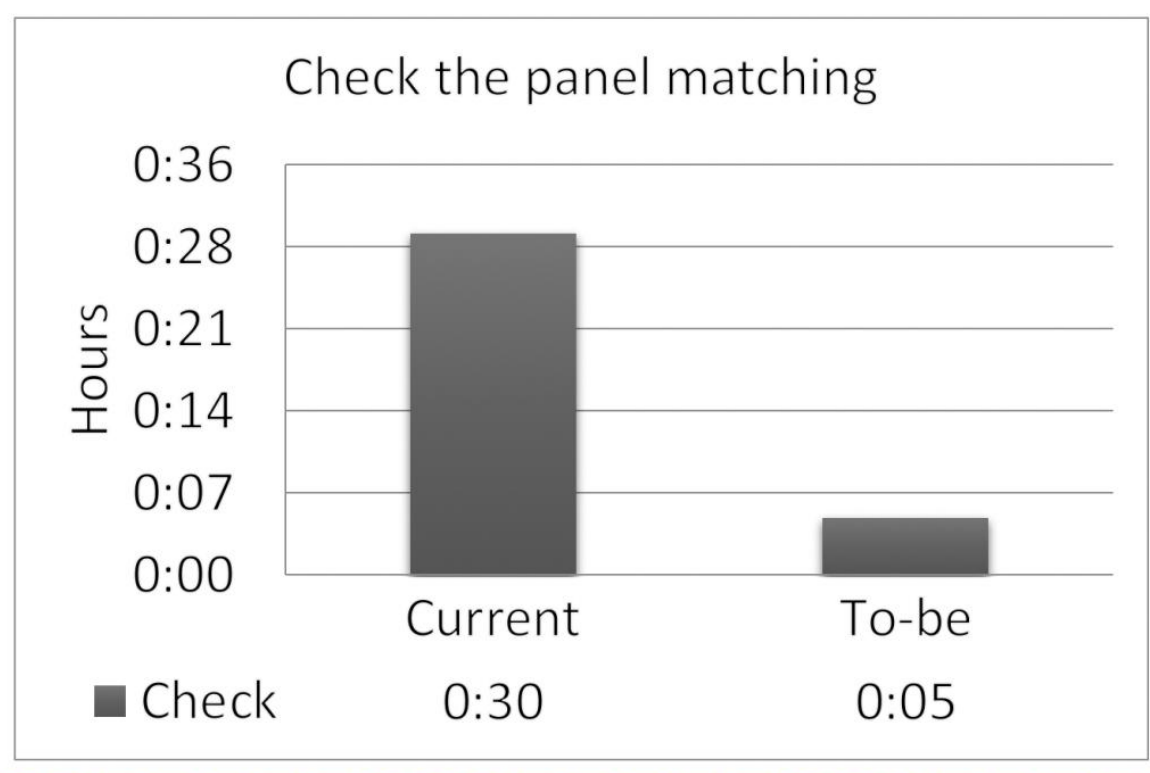

Fig.20.This charts showing the average wait time need it for check of each elements after arrival to site it's matching with erection sequence or not

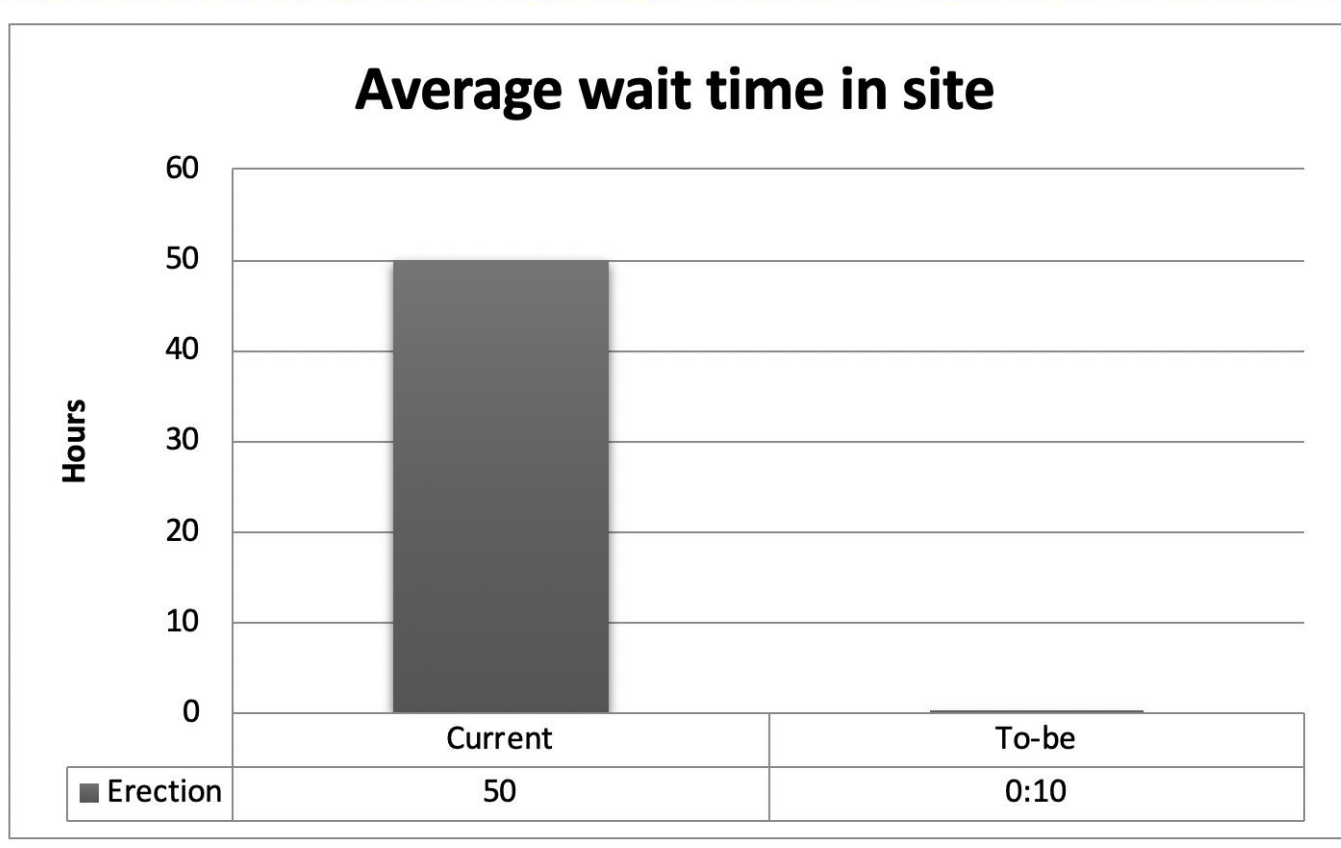

Fig.21.This charts showing the total average wait time for elements after arrival to site.

Comparison between two model

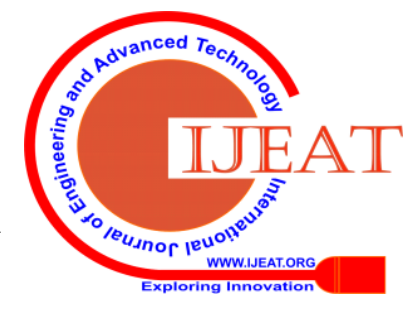


Development and Integration of RFID Simulation Based Tool for Improved Schedule Performance in Saudi Arabia Precast Concrete Industry
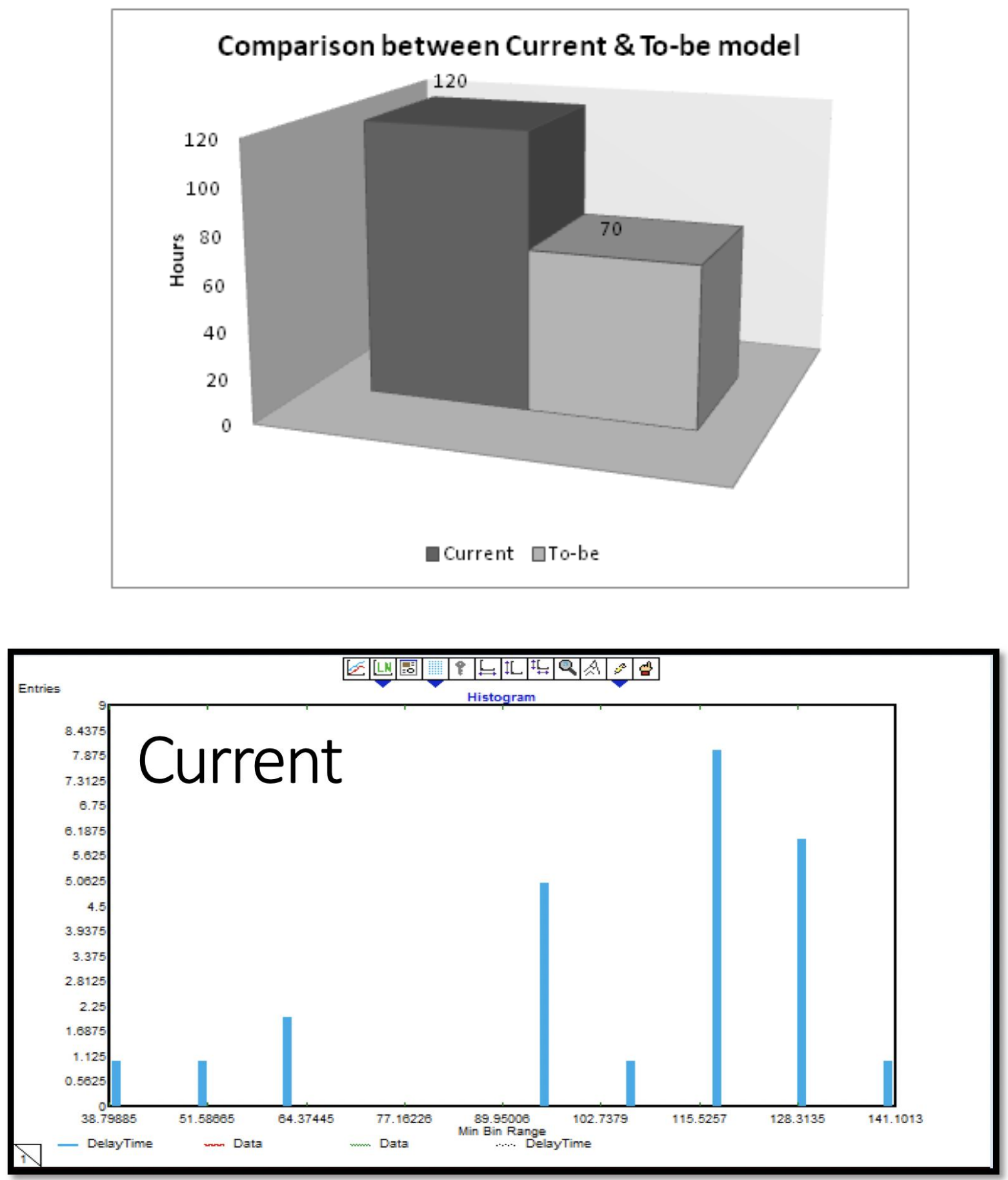

Fig.22. Most of element is overstock $84 \%$ from element is overstock

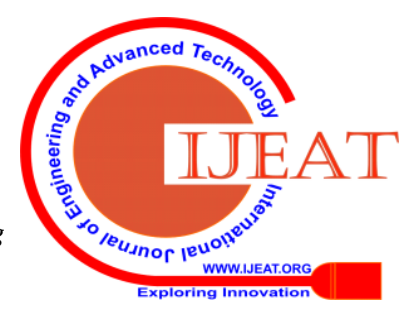




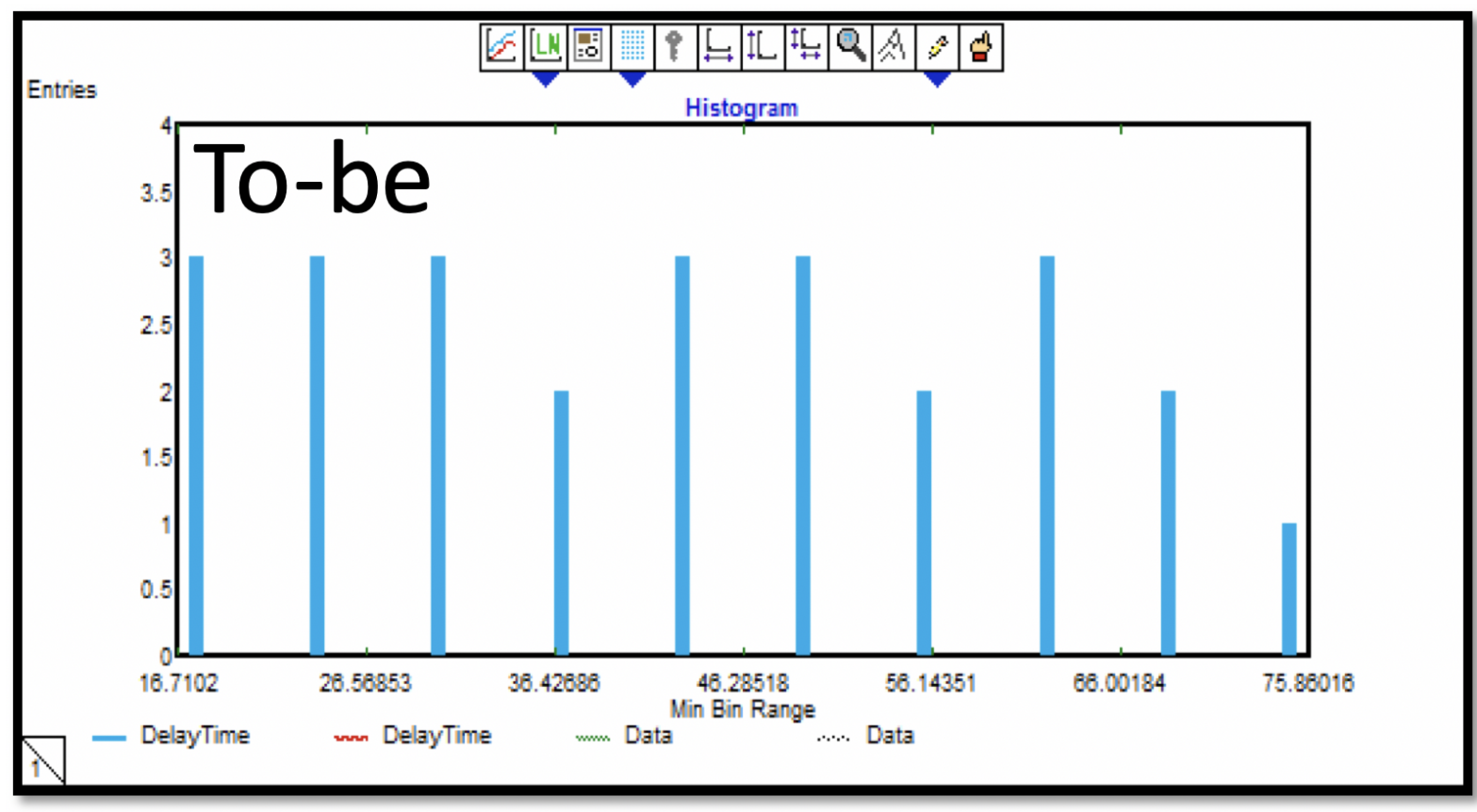

Fig.23. Uniform production \& transportation

IV.

DISCUSSION

enabled the construction industry to get rid of a claim to fame in associate degree exceptionally forceful market with the effective management and innovative frameworks the

$>$ Use RFID tags will reduce the time by $41 \%$ for preca production process. company has a great chance of being successful on a global scale.

$>$ RFID helps to reduce manpower for search and check panel

$>$ Reduce the double-handling and misplacement of elements. 1 .

$>$ Extend software improved site production layout.

\section{CONCLUSION}

Saudi Arabian housing industry is growing rapidly on a global as well as local scale with the capabilities of the industry it has a great number of chances of growing into the industry even with the presence of large companies. In order to improve the growth of the industry Saudi Arabian industry has adopted the strategy of RFID. Despite this case, and also the poor infamy of past would-be contenders, housing industry has had the flexibility to quickly originate and also make proximities in the Saudi Arabian industry. Feature of housing industry procedure has been chargeable for its success rather it's been associate degree outcome of a sometimes life-giving cluster of activities, i.e., "soundness". This case is addressed within the development structure. Saudi Arabian industry system to allow first class, insignificant toil things drive its thought on tip prime complete things, on discarding silly business limits and on building stores and relationship with employees and specialists to the extent that this is able to be attainable. Structure of housing industry with the adoption of RFID, spun around clear declaring lines and autonomous areas, and its low-tech undertakings, are expected for potency. RFID descent organization chips away at, as well as its assurance approaches, paying higher than respect pay, multi-skilling and arrangement of commitment are away to develop a submitted, capable, workforce. Having created a basic arrangement of activities to assist its imperative position has

\section{REFERENCE}

H. M. Taleb and S. Sharples, 'Developing sustainable residential buildings in Saudi Arabia: A case study', Appl. Energy, 2011.

2. R. A. Opoku and A. G. Abdul-Muhmin, 'Housing preferences and attribute importance among low-income consumers in Saudi Arabia', Habitat Int., 2010.

3. A. Al-Kharashi and M. Skitmore, 'Causes of delays in Saudi Arabian public sector construction projects', Constr. Manag. Econ., 2009.

4. M. Algahtany, Y. Alhammadi, and D. Kashiwagi, 'Introducing a New Risk Management Model to the Saudi Arabian Construction Industry', in Procedia Engineering, 2016.

5. G. Rice, 'Doing business in Saudi Arabia', Thunderbird Int. Bus Rev., 2004.

6. S. A. Assaf, A. A. Bubshaitr, and F. Al-Muwasheer, 'Factors affecting affordable housing cost in Saudi Arabia', Int. J. Hous. Mark. Anal., 2010.

7. S. Alqahtani and S. F. Wamba, 'Determinants of RFID technology adoption intention in the Saudi retail industry: An empirical study', in Proceedings of the Annual Hawaii International Conference on System Sciences, 2012.

8. A. H. Al-Hashedi, M. R. Mohd Arshad, A. S. Baharudin, and H. H. Mohamed, 'RFID applications in Hajj management system', in 2013 IEEE International Conference on RFID-Technologies and Applications, RFID-TA 2013, 2013.

9. S. Alqahtani and S. F. Wamba, 'Exploring technologicalorganizational and environmental characteristics related to RFID adoption intention in the Saudi Arabia's retail industry', in 2012 IEEE International Conference on RFID-Technologies and Applications, RFID-TA 2012, 2012

10. A. H. Al-Hashedi, M. R. M. Arshad, H. Hj Mohamed, and A. Suhaimi Baharuddin, 'Identifying the determinants of RFID adoption intention in Hajj organizations', in 2011 International Conference on Research and Innovation in Information Systems, ICRIIS'11, 2011.

Published By:

Blue Eyes Intelligence Engineering

\& Sciences Publication

(C) Copyright: All rights reserved.

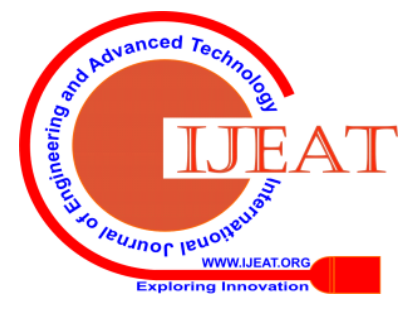




\section{Development and Integration of RFID Simulation Based Tool for Improved Schedule Performance in Saudi Arabia Precast Concrete Industry}

11. H. Binsalleeh, N. Mohammed, P. S. Sandhu, F. Aljumah, and B. C. M. Fung, 'Using RFID tags to improve pilgrimage management', in 2009 International Conference on Innovations in Information Technology, IIT '09, 2009.

12. N. Koshak and A. Nour, 'Integrating RFID and GIS to support urban transportation management and planning of hajj', in Proceedings of CUPUM 2013: 13th International Conference on Computers in Urban Planning and Urban Management - Planning Support Systems for Sustainable Urban Development, 2013.

13. E. A. Khan, 'An RFID-based system for pilgrim management in King AbdulAziz International Airport', in Proceedings - 2011 4th International Conference on Information Management, Innovation Management and Industrial Engineering, ICIII 2011, 2011.

14. M. Deriche and M. Mohandes, 'A hybrid RFID-LPR system for vehicle access control during Pilgrimage season in Saudi Arabia', in International Multi-Conference on Systems, Signals and Devices, SSD 2012 - Summary Proceedings, 2012.

15. D. M. Barakah and A. A. Kinani, 'Building smart Saudi hospitals using RFID technologies', in ICISO 2010 - Proceedings of the 12th International Conference on Informatics and Semiotics in Organisations, IFIP WG8.1 Working Conference, 2010.

16. Global Property Guide, 'Saudi Arabia's property market', 2012. [Online]. Available: https://www.globalpropertyguide.com/MiddleEast/Saudi-Arabia/Price-History-Archive/saudi-arabias-propertymarket-hot-hot-hot-127102.

17. K. V. S. Rao, P. V. Nikitin, and S. F. Lam, 'Antenna design for UHF RFID tags: A review and a practical application', IEEE Transactions on Antennas and Propagation. 2005.

18. G. Ferrer, N. Dew, and U. Apte, 'When is RFID right for your service?', Int. J. Prod. Econ., 2010.

19. F. Kamoun, 'RFID System Management ':, Network, 2009.

20. A. R. Sadeghi, I. Visconti, and C. Wachsmann, 'Enhancing RFID security and privacy by physically unclonable functions', in Information Security and Cryptography, 2010.

21. C. C. Tan and J. Wu, 'Security in RFID networks and communications', in Wireless Network Security: Theories and Applications, 2013.

22. P. V. Nikitin and K. V. S. Rao, 'Antennas and propagation in UHF RFID systems', in 2008 IEEE International Conference on RFID (Frequency Identification), IEEE RFID 2008, 2008.

23. J. Banks, M. Pachano, L. Thompson, and D. Hanny, RFID Applied. 2007.

24. N. Alharbe, A. S. Atkins, and A. S. Akbari, 'Application of ZigBee and RFID technologies in healthcare in conjunction with the interne of things', in ACM International Conference Proceeding Series, 2013.

25. M. Ramadan, H. Al-Maimani, and B. Noche, 'RFID-enabled smart real-time manufacturing cost tracking system', Int. J. Adv. Manuf. Technol., 2017.

26. A. M. Van Lieshout et al., 'RFID Technologies: Emerging Issues, Challenges and Policy Options', Challenges, 2007.

27. N. Li, G. Calis, and B. Becerik-Gerber, 'Measuring and monitoring occupancy with an RFID based system for demand-driven HVAC operations', Autom. Constr., 2012.

28. I. Chatzigiannakis, G. Mylonas, and A. Vitaletti, 'Urban pervasive applications: Challenges, scenarios and case studies', Comput. Sci. Rev., 2011.

29. L. Louw and M. Walker, 'Design and implementation of a low cost RFID track and trace system in a learning factory', in Procedia Manufacturing, 2018.

30. S. El-Omari and O. Moselhi, 'Integrating automated data acquisition technologies for progress reporting of construction projects', in 2009 26th International Symposium on Automation and Robotics in Construction, ISARC 2009, 2009.

31. S. El-Omari, 'Automated data acquisition for tracking and control of construction projects', Ph.D., Concordia Univ., 2008.

32. E. Ergen, B. Akinci, and R. Sacks, 'Tracking and locating components in a precast storage yard utilizing radio frequency identification technology and GPS', Autom. Constr., 2007.

33. E. Ergen and B. Akinci, 'An overview of approaches for utilizing RFID in construction industry', in 2007 1st Annual RFID Eurasia, 2007.

34. B. Akinci, M. Patton, and E. Ergen, 'Utilizing Radio-Frequency Identification on Precast Concrete Components - Supplier's Perspective', in Proceedings of the 19th International Symposium on Automation and Robotics in Construction (ISARC), 2017.

35. E. Ergen, 'Formalization of life -cycle data management of engineered -to -order components using advanced tracking technologies', 2005.

36. Z. Ren, C. J. Anumba, and J. Tah, 'RFID-facilitated construction materials management (RFID-CMM) - A case study of water-supply

\author{
project', Adv. Eng. Informatics, 2011.
}

37. J. H. Lee, J. H. Song, K. S. Oh, and N. Gu, 'Information lifecycle management with RFID for material control on construction sites', Adv. Eng. Informatics, 2013.

38. S. Y. L. Yin, H. P. Tserng, J. C. Wang, and S. C. Tsai, 'Developing a precast production management system using RFID technology', Autom. Constr., 2009.

39. L. Y. Ding and H. Li, 'Editorial: Information technologies in safety management of large-scale infrastructure projects', Automation in Construction, 2013.

40. H. P. Tserng, R. J. Dzeng, Y. C. Lin, and S. T. Lin, 'Mobile construction supply chain management using PDA and Bar Codes', Comput. Civ. Infrastruct. Eng., 2005.

41. '2013 2nd International Conference on Frontiers of Mechanical Engineering and Materials Engineering, MEME 2013', Applied Mechanics and Materials. 2014.

42. '2014 International Conference on Materials Science and Computational Engineering, ICMSCE 2014', Advanced Materials Research. 2014.

43. '2013 International Conference on Mechatronics and Information Technology, ICMIT 2013', Applied Mechanics and Materials. 2014.

44. Y. C. Lin, S. T. Lin, and H. P. Tserng, 'ConMBSCM: Construction mobile-based supply chain management system', in INNOVATIVE DEVELOPMENTS IN ARCHITECTURE, ENGINEERING AND CONTRUCTION, 2003.

45. J. Song, C. T. Haas, C. Caldas, E. Ergen, and B. Akinci, 'Automating the task of tracking the delivery and receipt of fabricated pipe spools in industrial projects', Autom. Constr., 2006.

46. J. Rekimoto, 'Pick-and-Drop: A direct manipulation technique for multiple computer environments', in UIST (User Interface Software and Technology): Proceedings of the ACM Symposium, 1997.

47. D. S. Ginger, H. Zhang, and C. A. Mirkin, 'The Evolution of Dip-Pen Nanolithography', Angewandte Chemie - International Edition. 2004.

48. S. Oviatt et al., 'Designing the user interface for multimodal speech and pen-based gesture applications: State-of-the-art systems and future research directions', Human-Computer Interact., 2000.

49. T. B. Moeslund and E. Granum, 'A survey of computer vision-based human motion capture', Comput. Vis. Image Underst., 2001.

50. F. Bosche and C. T. Haas, 'Automated retrieval of 3D CAD model objects in construction range images', Autom. Constr., 2008.

51. M. K. Reed, P. K. Allen, and I. Stamos, 'Automated model acquisition from range images with view planning', in Proceedings of the IEEE Computer Society Conference on Computer Vision and Pattern Recognition, 1997.

52. L. Ding, R. Drogemuller, M. Rosenman, and D. Marchant, 'Automating code checking for building designs - DesignCheck', Coop. Res. Cent. Constr. Innov., 2006.

53. G. Pomaska, 'Utilization of Photosynth Point Clouds for 3D Object Reconstruction', 22nd CIPA Symp., 2009.

54. Modernisation, Mechanisation and Industrialisation of Concrete Structures. 2017

55. M. Y. Cheng, M. H. Tsai, L. C. Lien, and W. N. Chen, 'OpenBuilding Maintenance management using RFID technology', in Automation and Robotics in Construction - Proceedings of the 24th International Symposium on Automation and Robotics in Construction, 2007.

56. O. Moselhi and A. Alshibani, 'Crew optimization in planning and control of earthmoving operations using spatial technologies', Electron. J. Inf. Technol. Constr., 2007.

57. A. Alshibani, 'Tracking and Control of Earthmoving Operations Using Spatial Technologies.', Cost Eng., 2008

58. C. M. Roberts, 'Radio frequency identification (RFID)', Comput. Secur., 2006

59. V. Rajaraman, 'Radio frequency identification', Resonance, 2017.

60. L. Identificaci, R. Frecuencia, and R. F. Identification, 'RFID: TECNOLOGÍA, APLICACIONES Y PERSPECTIVAS', Rfid Tecnol. Apl. Y Perspect., 2010.

61. S. A. Weis, 'RFID (Radio-Frequency Identification)', in Handbook of Computer Networks, 2012

62. V. D. Hunt, A. Puglia, and M. Puglia, RFID-A Guide to Radio Frequency Identification. 2006

63. B. Öztayşi, S. Baysan, and F. Akpinar, 'Radio frequency identification (RFID) in hospitality', Technovation, 2009

64. L. C. Wang, 'Enhancing construction quality inspection and management using RFID technology', Autom. Constr., 2008.

Published By:

Blue Eyes Intelligence Engineering

\& Sciences Publication

(c) Copyright: All rights reserved.

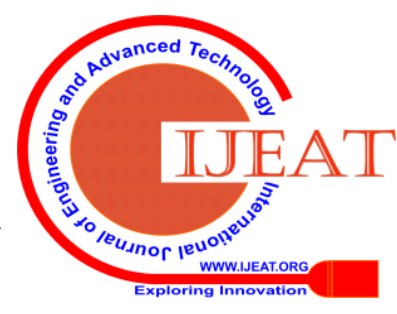


65. Z. Ma, S. Cai, N. Mao, Q. Yang, J. Feng, and P. Wang, 'Construction quality management based on a collaborative system using BIM and indoor positioning', Autom. Constr., 2018.

66. E. J. Jaselskis and T. El-Misalami, 'Implementing radio frequency identification in the construction process', J. Constr. Eng. Manag. 2003.

67. X. Wang, P. E. D. Love, M. J. Kim, C. S. Park, C. P. Sing, and L. Hou, 'A conceptual framework for integrating building information modeling with augmented reality', Autom. Constr., 2013.

68. A. Kelm et al., 'Mobile passive Radio Frequency Identification (RFID) portal for automated and rapid control of Personal Protective Equipment (PPE) on construction sites', Autom. Constr., 2013.

69. J. Sommerville and N. Craig, 'Intelligent buildings with radio frequency identification devices', Structural Survey. 2005.

70. C. Murphy, 'Real-World RFID: Wal-Mart, Gillette, and Others Share What They re Learning', InformationWeek, 2005.

71. D. A. Marchand, W. J. Kettinger, and J. D. Rollins, How Companies Win with the Right Information, People and IT. 2001.

72. C. Le-Pong and S. Yu-Shan, 'The study of performance improvements by implementation of RFID in the information production agent', in IET Conference Publications, 2006.

73. T. Omar and M. L. Nehdi, 'Data acquisition technologies for construction progress tracking', Automation in Construction. 2016.

74. F. Bosché, 'Plane-based registration of construction laser scans with 3D/4D building models', Adv. Eng. Informatics, 2012.

75. R. Maalek, J. Ruwanpura, and K. Ranaweera, 'Evaluation of the stateof-the-art automated construction progress monitoring and control systems', in Construction Research Congress 2014: Construction in a Global Network - Proceedings of the 2014 Construction Research Congress, 2014.

76. S. N. Razavi, A. Montaser, and O. Moselhi, 'RFID deployment protocols for indoor construction', Constr. Innov., 2012.

77. S. Seol, E. K. Lee, and W. Kim, 'Indoor mobile object tracking using RFID’, Futur. Gener. Comput. Syst., 2017.

78. F. Bergeron, K. Bouchard, S. Gaboury, and S. Giroux, 'Tracking objects within a smart home', Expert Syst. Appl., 2018.

79. N. Li, S. Li, B. Becerik-Gerber, and G. Calis, 'Deployment strategies and performance evaluation of a virtual-tag-enabled indoor location sensing approach', J. Comput. Civ. Eng., 2012.

80. J. A. Hartigan and M. A. Wong, 'Algorithm AS 136: A K-Means Clustering Algorithm', Appl. Stat., 1979.

81. A. Hartigan and M. A. Wong, 'A K-Means Clustering Algorithm', J. R. Stat. Soc., 1979.

82. D. T. Pham, S. S. Dimov, and C. D. Nguyen, 'Selection of K in Kmeans clustering', Proc. Inst. Mech. Eng. Part C J. Mech. Eng. Sci., 2005.

83. D. Yates, S. Gangopadhyay, B. Rajagopalan, and K. Strzepek, 'A technique for generating regional climate scenarios using a nearestneighbor algorithm', Water Resour. Res., 2003. 